\title{
Effect of Biofertilization and Silicon Foliar Application on Productivity of Sunflower (Helianthus annuus L.) under New Valley Conditions
}

\author{
A.M. Abd El-Gwad* and E.M.M. Salem ${ }^{* *}$ \\ *Soil Fertility and Microbiology Department and ${ }^{* *}$ Agronomy \\ Unit, Plant Production Department, Desert Research Center, \\ Cairo, Egypt.
}

\begin{abstract}
WWO field experiments were carried out at Desert Research Center (D.R.C.), Agricultural Experimental Station at EL-Kharga, New Valley Governorate, during the two summer growing seasons of 2010 and 2011, these experiments aimed to study the effect of biofertilization (Azotobacter chroococcum, Bacillus megatherium (PDB) and mixture of two isolates) and silicon spraying rates (200, $400,600,800$ and $1000 \mathrm{mg} / \mathrm{L}$.) against control on the productivity of Sunflower (Helianthus annuus L.) by using cultivar Sakha 53. The experiments were laid out in a split plot design with four replicates. Foliar application of silicon treatments were arranged in the main plots and biofertilization treatments in the sub-plots.
\end{abstract}

Results showed that both spraying silicon and biofertilization treatments had enhancement effect on plant height, number of leaves, leaves surface area, fresh and dry weight of leaves/plant and stem diameter, also head diameter, seeds number/head and 100-seed weight as well as seed and straw yields. Moreover, seed oil percentage and oil yield. The enhancement effect of all abovementioned traits with inoculation of Azotobacter chroococcum, PDB individual or mixed compared with the control treatment (without biofertilization). Also, remarkable influence of the interaction between silicon foliar application and biofertilization treatments on all yield and yield components. Results also indicated significant microbial activity in rhizosphere soil expressed by total microbial counts, $\mathrm{CO}_{2}$ evolution, Azotobacter and Phosphate dissolving bacteria counts and Enzymatic activities (Dehydrogenase,Nitrogenase and Phosphatase) exihibited positive response in all treatments compared to uninoculated control.

Keywords: Sunflower, Silicon, Biofertilization, Azotobacter chroococcum, Bacillus megatherium, Yield and its components and Oil yield.

New Valley governorate, is one of the most promising newly reclaimed lands in Egypt, one and represents large land resources for agriculture expansion. Weather in this region is hot and dry, and cultivation depends mainly on ground water. So agriculture expansion in this region needs application of special practices for the best use of land and water resources. 
Sunflower (Helianthus annuus, L.) considered one of the major sources of edible vegetable oil in the world and also in Egypt due to its high unsaturated fatty acids content (Leland, 1996). So, there is need to increase the oil yield to enhance food security.

Nitrogen deficiency in Egyptian soils is one of the most limiting factors for Sunflower production. Therefore fertilizer application either organic or inorganic becomes a major practice towards yield increase. Phosphorus (P) has similar importance for the growth of Sunflower, its deficiency results in stunted growth, purplish discoloration of leaves. It also affects flowering, fruit formation and seed production (Aduayi et al., 2002). Uptake of major nutrients elements by sunflower has also been reported to be facilitated on $\mathrm{P}$ was application (Fagbayide and Adeoye, 1999). Several investigators showed the effect of mineral and organic fertilizers application on sunflower as, Abou khadrah et al. (2002), Mohamed (2003), Awad (2004), Mohamed and Ayman (2009).

The biofertilizers considered one of the sources for supplying nutrients for the crops and conserve the environment from pollution by excessive use of mineral $\mathrm{N}$ fertilizer. The beneficial effect of biofertilizers, viz. Azospirillum and Azotobacter inoculation on sunflower has been reported by several investigators. Saleh et al. (2004) studied the response of some sunflower cultivars to Rhizobacterien as biofertilizers as comparing with mineral nitrogen, they reported that all studied characters were significantly increased by increasing nitrogen levels up to $30 \mathrm{~kg} \mathrm{~N}$ /fed or inoculation of sunflower seed with Rhizobacterien plus application of $20 \mathrm{~kg} \mathrm{~N} / \mathrm{fed}$. Mohamed (2003) and Abou khadrah et al. (2002) revealed that the inoculation of sunflower seed with $\left(\mathrm{N}_{2}\right.$ fixing) bacteria (Cerealin) or with phosphate dissolving bacteria (Phosphorine) or with combined of the two biofertilizers significantly enhanced all the studied traits over the control (dry matter accumulation/plant in some growth stages, head diameter, number of seeds/head, seed oil content, seed yield/plant as well as seed and oil yields/fed). Nawar (1994) and Radwan (1996) reported that inoculation of sunflower seed with phosphate dissolving bacteria (phosphorine) significantly increased number and weight of seeds/head and head diameter in addition to growth attributes.

The results obtained by Keshta and El-Kholy (1999) indicated that application of inorganic nitrogen and biofertilizers as a source of $\mathrm{N}_{2}$ fixing bacteria for sunflower increased plant height, head diameter,100- seed weight, seed yield/fed and seed oil content.

Some free living microorganisms in soil have capability to produce extracellular enzymes such as phosphatase (George et al., 2002), this enzyme able to mineralize organic phosphates into inorganic phosphates that provides high $\mathrm{P}$ for plant. Soil phosphatases play a major role in the mineralization processes (dephosphorilation) of organic $\mathrm{P}$ substrates. The use of phosphate solubilizing bacteria as inoculants simultaneously increases $\mathrm{P}$ uptake by the plant and crop yield.

Egypt. J. Soil Sci. 53, No. 4 (2013) 
Silicon is required as a nutrient for normal growth in wetland species of the families Gramineae, Equisetaceae and some Cyperaceae but in dicotyledons and other grasses, its role remains elusive (Chen and Lewin, 1968, Kaufman et al., 1985, Takahashi et al., 1990, Lewin and Reimann, 1969 and Fawe et al., 1998). There are several hypotheses concerning the role of $\mathrm{Si}$ in dicots and nonaccumulator grasses including a positive effect on reproduction, alleviation of metal toxicity and nutrient imbalance, provision of structural rigidity and increased resistance to fungal diseases such as powdery mildews and root rots (Epstein, 1994 and Belanger et al., 1995). Recent work contended that Si may act by stimulating the natural defense mechanisms of the plant (Belanger et al., 1995).

It has been reported that adding silicon to monocots, especially Gramineae plants, not only promotes growth and development but also promotes photosynthesis, reduces pest infection, maintains the shoot in an erect position and alleviates salt stress (Ahmad et al., 1992, Epstein, 1999, Korndorfer and Lepsch, 2001 and Ma, 2004). It is found in the soil in the form of silicic acid (Chen et al., 2010) and all plant species take it in the form of silicic acid (Ma et al., 2001). Different studies indicated positive effect of silicon application on the plant growth and development including enhanced pollination, increase dry biomass and final yield (Korndorfer and Lepsch, 2001) and resistance against various diseases (Gillman et al., 2003). Application of Si could alleviate the oxidative stress of wheat and regulate activities of antioxidant enzymes, which contributed to improvement of growth of plants under drought (Gong et al., 2008).

Silicon considered to be important element under stress because it increased drought tolerance in plants by maintaining leaf water potential, assimilation of $\mathrm{CO}_{2}$ and reduction in transpiration rates by adjusting plant leaf area (Hattori et al., 2005). Maintenance of higher leaf water potential under stress is one of remarkable feature which silicon nutrition does for plants as reported by Lux et al. (2002). Silicon was reported to enhance growth of many plants particularly under biotic and abiotic stresses (Epstein, 1999). A number of possible mechanisms have been proposed by which $\mathrm{Si}$ would increase resistance of plants against salinity stress which is a major yield limiting factor in arid and semiarid areas. (AlAghabary et al., 2004).

The objective of this investigation was to study the effect of the application of silicon foliar and biofertilization on Sunflower production under New Valley conditions.

\section{Material and Methods}

Two field experiments were conducted at the Agriculture Experimental station at El-Kharga Oasis (30.53 longitude, 24.45 latitude and elevation 78.8), New Valley Governorate, Desert Research Center (DRC), Egypt during the two summer growing seasons of 2010 and 2011 to study the effect of biofertilization (Azotobacter chroococcum and Bacillus megatherium) and silicon foliar 
application on productivity of Sunflower. Representative soil samples were taken from the experimental sites at depth from 0 to $30 \mathrm{~cm}$ from soil surface and were prepared for both mechanical and chemical analysis.

The experiment was laid out in a split plot design with four replicates. Foliar application of silicon treatments were allocated the main plots and biofertilization treatments occupied the sub-plots. Each plot was $12 \mathrm{~m}^{2}$ contained five ridges (4 m length and $60 \mathrm{~cm}$ width with hills $20 \mathrm{~cm}$ apart).

Each experiment included twenty four treatments which were the combinations of six silicon spraying rates (control, 200, 400, 600, 800 and 1000 $\mathrm{mg} / \mathrm{L}$ ) and four biofertilization treatments (control, Azotobacter chroococcum, Bacillus megatherium (PDB) and mixture of the two isolates).

Seeds of sunflower (Helianthus annuus, L.) cultivar Sakha 53 were sown on May 22 and 26 in the first and second seasons, respectively. Also, sheep manure of $20 \mathrm{~m}^{3} /$ feddan as organic manure containing O.C $25 \%, \mathrm{~N} 2.17 \%, \mathrm{C} / \mathrm{N}$ ratio 11.52 and O.M $43 \%$. Calcium super phosphate (15.5\% P2O5) was applied at the rate of $31 \mathrm{~kg} \mathrm{P}_{2} \mathrm{O}_{5} /$ feddan during land preparation, before sowing, $\mathrm{N}$ and $\mathrm{K}$ fertilizers were added at the rate of $60 \mathrm{Kg} \mathrm{N} / \mathrm{fed}$ as $\left(\mathrm{NH}_{4}\right)_{2} \mathrm{SO}_{4}$ and $75 \mathrm{Kg}$ $\mathrm{K}_{2} \mathrm{O}$ /fed as $\mathrm{K}_{2} \mathrm{SO}_{4}$ with three equal doses.

\section{Bacterial culture preparation}

The systematic biotechnology was used taking fresh liquid cultures $48 \mathrm{hr}$ old from pure local strains of $A$. chroococcum and $B$. megatherium var. phosphaticum, previously isolated from the rhizosphere soils of New Valley Governorate, purified and identified according to Bergey's Manual (1984) as biofertilizers in the form of single or mixed inoculations at the rate of $\sim 10^{8} \mathrm{cfu} / \mathrm{ml}$.

\section{Application methods}

Bacterial strains were applied separately or in combination as soil drench. Sunflower seeds were soaked in a single or mixture of bacterial isolates suspensions $\left(10^{8} \mathrm{cfu} / \mathrm{ml}\right)$ for $3 \mathrm{hr}$ before planting (carboxyl methyl cellulose $0.5 \%$ was used as an adhesive agent). Seeds of the control plots were soaked in water only. An additional dose was applied twenty one days later once again to soil.

\section{Silicon application}

Silicon was applied as a foliar spray at a concentration of 200, 400, 600, 800 and $1000 \mathrm{mg} / \mathrm{L}$ at 40 days from planting. Knapsack sprayer with water volume of $300 \mathrm{~L} /$ fed were used.

Soil was directly irrigated after planting to provide suitable moisture for the inoculants. Thinning practices were conducted 21 days after planting to secure one plant per hill. Other practices for growing sunflower were conducted as recommended. 
The physical and chemical analysis of soil and irrigation water were presented in Tables 1 and 2 .

TABLE 1. Some physical and chemical properties of the experimental soil.

\begin{tabular}{|c|c|c|c|c|c|c|c|c|c|c|}
\hline \multicolumn{11}{|c|}{ Mechanical analysis } \\
\hline \multicolumn{3}{|c|}{ Sand } & \multicolumn{3}{|c|}{ Clay } & \multicolumn{2}{|c|}{ Silt } & \multicolumn{3}{|c|}{ Soil Texture } \\
\hline \multicolumn{3}{|c|}{$50.2 \%$} & \multicolumn{3}{|c|}{$31.5 \%$} & \multicolumn{2}{|c|}{$18.3 \%$} & \multicolumn{3}{|c|}{ Sandy clay loam } \\
\hline \multicolumn{11}{|c|}{ Chemical analysis } \\
\hline \multirow[t]{2}{*}{$\mathbf{p H}$} & \multirow{2}{*}{$\begin{array}{c}\text { EC } \\
\mathrm{dS} / \mathrm{cm}\end{array}$} & \multirow{2}{*}{ T.N } & \multicolumn{4}{|c|}{ Cations (meq/L) } & \multicolumn{4}{|c|}{ Anions (meq/L) } \\
\hline & & & $\mathrm{Ca}^{+2}$ & $\mathrm{Mg}^{+2}$ & $\mathbf{K}^{+}$ & $\mathrm{Na}^{+}$ & $\mathrm{CO}_{3}{ }^{-2}$ & $\mathrm{HCO}^{-3}$ & $\mathrm{Cl}^{-}$ & $\mathrm{SO}_{4}^{-2}$ \\
\hline 8.32 & 4.35 & $\begin{array}{l}100 \\
\mathrm{ppm}\end{array}$ & 9.1 & 2.45 & 1.98 & 29.11 & 0.00 & 8 & 26.6 & 8.04 \\
\hline \multicolumn{11}{|c|}{ Trace elements (mg/l) } \\
\hline \multicolumn{2}{|c|}{$\mathbf{Z n}$} & \multicolumn{2}{|c|}{ Mn } & \multicolumn{2}{|c|}{$\mathbf{C u}$} & \multicolumn{2}{|c|}{$\mathbf{F e}$} & \multicolumn{3}{|c|}{ B } \\
\hline \multicolumn{2}{|c|}{5.93} & \multicolumn{2}{|c|}{4.04} & \multicolumn{2}{|c|}{1.82} & \multicolumn{2}{|c|}{33.1} & \multicolumn{3}{|c|}{0.58} \\
\hline
\end{tabular}

TABLE 2. Chemical analysis of irrigation water.

\begin{tabular}{|c|c|c|c|c|c|c|c|c|c|}
\hline \multirow{3}{*}{ pH } & \multirow{3}{*}{$\begin{array}{c}\text { E.C } \\
\text { D } \\
\text { S/cm }\end{array}$} & \multicolumn{8}{|c|}{ Soluble ions (ppm) } \\
\hline & & \multicolumn{4}{|c|}{ Cations } & \multicolumn{4}{|c|}{ Anions } \\
\hline & & $\mathrm{Ca}^{+2}$ & $\mathrm{Mg}^{+2}$ & $\mathrm{Na}^{+}$ & $\mathbf{K}^{+}$ & $\mathrm{CO}_{3}^{-2}$ & $\mathrm{HCO}_{3}^{-}$ & $\mathrm{Cl}^{-}$ & $\mathrm{SO}_{4}^{-2}$ \\
\hline 7.4 & 730 & 19.61 & 11.91 & 88 & 22 & - & 230.15 & 74.2 & 29.38 \\
\hline
\end{tabular}

\section{Assessments}

A. Growth traits

After 60 days from sowing, five guarded plants were chosen randomly from each experimental unit of four replicates to estimate plant height, number of leaves/plant, fresh and dry leaves weight /plant, stem diameter and leaf surface area computed as described by Bremner and Taha (1966).

\section{B.Yield and its attributes}

Ten guarded plants at harvest were randomly taken from each plot and the following characters were determined: head diameter $(\mathrm{cm})$, number of seeds/head and 100-seeds weight $(\mathrm{g})$. Moreover, all plants of the experimental unit $\left(12 \mathrm{~m}^{2}\right)$ were harvested to evaluate seed and Straw yields.

\section{Seed chemical composition}

Samples of sunflower seeds were dried at $70^{\circ} \mathrm{C}$ for $24 \mathrm{hr}$ and seed oil content was determined according to A.O.A.C. (1980) using soxhlet apparatus and diethyl ether as a solvent, then oil yield ( $\mathrm{kg} / \mathrm{fed}$.) was calculated by multiplying seed yield $(\mathrm{kg} / \mathrm{fed})$ by seed oil content. 


\section{Microbial determinations}

Soil samples of sunflower rhizosphere were collected at flowering and harvesting stage of sunflower plant growth and analyzed for total count of microorganisms according to Nautiyal (1999) using the decimal plate method technique. For counting and growing phosphate dissolving bacteria using Bunt and Rovira medium as described by Abd El- Hafez (1966). For Azotobacter densities, nitrogen deficient medium was used as described by Abd El-Malek and Ishac (1968). $\mathrm{CO}_{2}$ evolution according to Anderson (1982).

Soil samples were analyzed for: Dehydrogenase activity according to method described by Casida et al. (1964). Nitrogenase activity was measured using a standard acetylene reduction assay as described by Haahtela et al. (1981). For determination of phosphatase activity Disodium phenylphosphate served as enzyme substrate (Õhlinger, 1996), alkaline phosphatase activity was measured in reaction mixture treated with borax buffer (PH4.9). The reaction mixtures consisted of $2.5 \mathrm{~g}$ soil, $2 \mathrm{ml}$ toluene (antiseptic), $10 \mathrm{ml}$ buffer solution and $10 \mathrm{ml}$ $0.5 \%$ substrate solution. Reaction mixtures without soil or without substrate solution were the control. All reaction mixtures were incubated at $37^{\circ} \mathrm{C}$ for $2 \mathrm{hr}$. After incubation, the phenol released from the substrate under the action of phosphatases was determined spectrophotometrically (at $614 \mathrm{~nm}$ ) based on the colour reaction between phenol and 2,6-dibromoquinone-4-chloroimide. Phosphatase activity is expressed in $\mathrm{mg}$ phenol/g soil/2 hr.

\section{Statistical analysis}

All the obtained data from each season were exposed to the proper statistical analysis of variance according to Gomez and Gomez (1984). LSD at 0.05 level of significance was used for the comparison between means.

\section{Results and Discussion}

\section{Growth traits}

Growth parameters values during 2010 and 2011 seasons were shown in Table 3. Results indicated that gradual increase in sunflower plant height, number of leaves, leaves surface area, fresh and dry weight of leaves/plant and stem diameter were observed with increasing concentrations of silicon up to $1000 \mathrm{mg} / \mathrm{l}$ and biofertilization using Azotobacter chroococcum as nitrogen fixer and Bacillus megatherium as phosphate dissolving bacteria (individual and mixed treatments). Interaction of biofertilization with silicon foliar application resulted in increasing abovementioned growth parameters. The highest increase was recorded with mixed biofertilization treatment and silicon foliar application $(1000 \mathrm{mg} / \mathrm{L}$.), where the highest \% of increase than control was recorded being $43 \%$ and $45 \%$ for plant height, $62 \%$ and $68 \%$ for No of leaves, $23 \%$ and $39 \%$ for leaf area, $67 \%$ and $75 \%$ for fresh weight, $116 \%$ and $126 \%$ for dry weight, $62 \%$ and $65 \%$ for stem diameter at first and second season, respectively.

Egypt. J. Soil Sci. 53, No. 4 (2013) 
EFFECT OF BIOFERTILIZATION AND SILICON FOLIAR...

TABLE 3. Effect of silicon foliar application and biofertilization on growth traits of sunflower after 60 days from sowing (2010 growing season).

\begin{tabular}{|c|c|c|c|c|c|c|c|c|c|c|}
\hline \multirow{2}{*}{ Silicon bio } & \multicolumn{5}{|c|}{ Plant height $(\mathrm{cm}) 1^{s t}$ season } & \multicolumn{5}{|c|}{ Plant height $(\mathrm{cm}) 2^{\text {nd }}$ season } \\
\hline & Cont. & Azoto & PDB & Mix & Mean & Cont. & Azoto & PDB & Mix & Mean \\
\hline 0 & 140 & 149 & 145 & 158 & 148 & 142 & 153 & 149 & 163 & 151.8 \\
\hline 200 & 143 & 152 & 148 & 165 & 152 & 148 & 156 & 151 & 172 & 156.8 \\
\hline 400 & 151 & 159 & 154 & 171 & 158.8 & 153 & 162 & 159 & 177 & 162.8 \\
\hline 600 & 156 & 162 & 158 & 179 & 163.8 & 159 & 167 & 166 & 184 & 169 \\
\hline 800 & 160 & 169 & 165 & 183 & 169.3 & 162 & 173 & 170 & 195 & 175 \\
\hline 1000 & 165 & 174 & 170 & 188 & 174.3 & 168 & 178 & 173 & 206 & 181.3 \\
\hline Mean & 152.5 & 160.8 & 156.7 & 174 & 161 & 155.3 & 164.8 & 161.3 & 182.8 & 166.1 \\
\hline $\begin{array}{l}\text { L.S.D } \\
\text { Silicon } \\
0.05 \% \text { Bio. } \\
\text { interaction }\end{array}$ & \multicolumn{5}{|l|}{$\begin{array}{l}1.388 \\
1.133 \\
4.161\end{array}$} & \multicolumn{5}{|l|}{$\begin{array}{l}1.647 \\
1.345 \\
4.027\end{array}$} \\
\hline \multicolumn{6}{|c|}{ No. of leaves $/$ plant $1^{\text {st }}$ season } & \multicolumn{5}{|c|}{ No. of leaves /plant $2^{\text {nd }}$ season } \\
\hline 0 & 21 & 26 & 23.8 & 27.8 & 24.7 & 21.9 & 29.5 & 25.4 & 29.8 & 26.7 \\
\hline 200 & 22.9 & 26.4 & 24.1 & 28.5 & 25.5 & 24.5 & 28.1 & 25.6 & 30.2 & 27.1 \\
\hline 400 & 24.6 & 26.7 & 25.3 & 29.8 & 26.6 & 26.3 & 28.4 & 26.8 & 31.9 & 28.4 \\
\hline 600 & 25.3 & 27.7 & 26.4 & 31.5 & 27.7 & 26.8 & 29.3 & 28.2 & 33.4 & 29.4 \\
\hline 800 & 26.8 & 28.2 & 27.2 & 33.1 & 28.8 & 27 & 29.7 & 28.8 & 35.8 & 30.3 \\
\hline 1000 & 27 & 29.6 & 28.3 & 34 & 29.7 & 28.6 & 32.4 & 30.6 & 37.4 & 32.3 \\
\hline Mean & 24.6 & 27.4 & 25.9 & 30.8 & 27.2 & 25.9 & 29.6 & 27.6 & 33.1 & 29 \\
\hline $\begin{array}{l}\text { L.S.D } \\
\text { Silicon } \\
0.05 \% \text { Bio. } \\
\text { interaction }\end{array}$ & \multicolumn{5}{|l|}{$\begin{array}{l}0.408 \\
0.333 \\
2.462\end{array}$} & \multicolumn{5}{|l|}{$\begin{array}{l}0.581 \\
0.474 \\
2.034\end{array}$} \\
\hline \multicolumn{6}{|c|}{ Leaves surface area $\left(\mathrm{cm}^{2}\right) 1^{s t}$ season } & \multicolumn{5}{|c|}{ Leaves surface area $\left(\mathrm{cm}^{2}\right) 2^{\text {nd }}$ season } \\
\hline 0 & 66.5 & 71.5 & 70 & 72.8 & 70.2 & 67 & 72.3 & 72 & 74 & 71.325 \\
\hline 200 & 69 & 72.5 & 72.4 & 76.3 & 72.6 & 69.8 & 73.2 & 73.6 & 77.8 & 73.6 \\
\hline 400 & 69.8 & 75 & 73 & 79 & 74.2 & 70.9 & 75.6 & 74.1 & 81 & 75.4 \\
\hline 600 & 72.3 & 78 & 75.7 & 81.4 & 76.9 & 73.4 & 79.2 & 76.5 & 84 & 78.275 \\
\hline 800 & 73.1 & 79.8 & 77.6 & 85.6 & 79 & 75.2 & 80.4 & 79 & 87 & 80.4 \\
\hline 1000 & 74.6 & 81.1 & 79.2 & 88.4 & 80.8 & 76.8 & 85.7 & 80.6 & 93 & 84.025 \\
\hline Mean & 70.9 & 76.3 & 74.7 & 80.6 & 75.6 & 72.2 & 77.7 & 76 & 82.8 & 77.1708 \\
\hline $\begin{array}{l}\text { L.S.D. } \\
(\% 0.05) \\
\text { Silicon } \\
\text { con. Bio. } \\
\text { interaction }\end{array}$ & \multicolumn{5}{|l|}{$\begin{array}{l}0.533 \\
0.435 \\
0.915\end{array}$} & \multicolumn{5}{|l|}{$\begin{array}{l}0.505 \\
0.567 \\
2.404\end{array}$} \\
\hline \multicolumn{6}{|c|}{ Stem diameter $(\mathrm{cm}) 1^{\text {st }}$ season } & \multicolumn{5}{|c|}{ Stem diameter $(\mathrm{cm}) 2^{\text {nd }}$ season } \\
\hline 0 & 1.42 & 1.69 & 1.6 & 1.73 & 1.61 & 1.54 & 1.85 & 1.74 & 1.94 & 1.7675 \\
\hline 200 & 1.51 & 1.69 & 1.63 & 1.75 & 1.65 & 1.72 & 1.87 & 1.79 & 2.11 & 1.8725 \\
\hline 400 & 1.59 & 1.7 & 1.65 & 1.89 & 1.71 & 1.79 & 1.93 & 1.8 & 2.29 & 1.9525 \\
\hline 600 & 1.62 & 1.73 & 1.69 & 2.08 & 1.78 & 1.85 & 1.97 & 1.84 & 2.45 & 2.0275 \\
\hline 800 & 1.67 & 1.84 & 1.73 & 2.26 & 1.88 & 1.92 & 2.03 & 1.89 & 2.49 & 2.0825 \\
\hline 1000 & 1.75 & 1.9 & 1.78 & 2.3 & 1.93 & 1.98 & 2.25 & 2.01 & 2.54 & 2.195 \\
\hline Mean & 1.6 & 1.8 & 1.68 & 2 & 1.76 & 1.8 & 1.98 & 1.85 & 2.30 & 1.98292 \\
\hline $\begin{array}{l}\text { L.S.D. } \\
(\% 0.05) \\
\text { Silicon } \\
\text { con. Bio. } \\
\text { interaction }\end{array}$ & \multicolumn{5}{|l|}{$\begin{array}{l}0.038 \\
0.031 \\
1.122\end{array}$} & \multicolumn{5}{|l|}{$\begin{array}{l}0.035 \\
0.029 \\
0.019\end{array}$} \\
\hline
\end{tabular}

Egypt. J. Soil Sci. 53, No.4 (2013) 
TABLE 3. Contd.

\begin{tabular}{|c|c|c|c|c|c|c|c|c|c|c|}
\hline \multirow{2}{*}{ Silicon } & \multicolumn{5}{|c|}{$\begin{array}{c}\begin{array}{c}\text { Fresh weight of leaves/ plant }(\mathrm{g}) 1^{\text {st }} \\
\text { season }\end{array} \\
\end{array}$} & \multicolumn{5}{|c|}{$\begin{array}{l}\text { Fresh weight of leaves/plant }(\mathrm{g}) 2^{\text {nd }} \\
\text { season }\end{array}$} \\
\hline & Cont. & Azoto & PDB & Mix & Mean & Cont. & Azoto & PDB & Mix & Mean \\
\hline 0 & 104.2 & 109.1 & 107 & 114 & 108.6 & 106 & 111.3 & 110.2 & 116.9 & 111.1 \\
\hline 200 & 106.1 & 112.8 & 109.6 & 117 & 111.4 & 108.1 & 115.3 & 113.8 & 119.7 & 114.2 \\
\hline 400 & 109.1 & 117.6 & 115 & 120.4 & 115.5 & 111.4 & 121 & 117.4 & 123.9 & 118.4 \\
\hline 600 & 111.6 & 123 & 117.8 & 130.8 & 120.8 & 114.3 & 125.5 & 120.1 & 135 & 123.7 \\
\hline 800 & 112.9 & 126 & 122.4 & 148 & 127.3 & 115.8 & 133 & 125.6 & 154 & 132.1 \\
\hline 1000 & 117.3 & 149 & 134 & 174 & 143.6 & 119.5 & 175 & 138 & 181 & 153.4 \\
\hline Mean & 110.2 & 122.9 & 117.6 & 134 & 121.2 & 112.5 & 130.2 & 120.9 & 138.4 & 125.5 \\
\hline $\begin{array}{l}\text { L.S.D. } \\
(\% 0.05) \\
\text { Silicon } \\
\text { con. Bio. } \\
\text { interaction }\end{array}$ & \multicolumn{5}{|l|}{\begin{tabular}{|l|}
1.64 \\
0.858 \\
1.69
\end{tabular}} & \multicolumn{5}{|l|}{\begin{tabular}{|l|}
0.503 \\
0.411 \\
0.376 \\
\end{tabular}} \\
\hline \multicolumn{6}{|c|}{ Dry weight of leaves/ plant (g) $1^{s t}$ season } & \multicolumn{5}{|c|}{ Dry weight of leaves/plant $(\mathrm{g}) 2^{\text {nd }}$ season } \\
\hline 0 & 22.9 & 24.6 & 23.7 & 26.2 & 24.4 & 23.1 & 25.3 & 24.2 & 28 & 25.2 \\
\hline 200 & 23.9 & 26.3 & 24.8 & 28.2 & 25.8 & 25 & 28 & 25.3 & 30 & 27.1 \\
\hline 400 & 25.4 & 29 & 26.8 & 32.7 & 28.5 & 26.1 & 31.2 & 27.6 & 34 & 29.7 \\
\hline 600 & 25.8 & 36.2 & 31.8 & 40.2 & 33.5 & 27.3 & 37.4 & 34.5 & 41.8 & 35.2 \\
\hline 800 & 27.2 & 37.5 & 33.9 & 46.8 & 36.4 & 27.6 & 39.7 & 35.5 & 48.2 & 37.8 \\
\hline 1000 & 29.3 & 40.8 & 38 & 49.6 & 39.4 & 30.8 & 42 & 40.7 & 42.3 & 39 \\
\hline Mean & 25.8 & 32.4 & 29.9 & 37.3 & 31.3 & 26.7 & 33.9 & 31.3 & 37.4 & 32.3 \\
\hline $\begin{array}{l}\text { L.S.D. } \\
(\% 0.05) \\
\text { Silicon } \\
\text { con. Bio. } \\
\text { interaction }\end{array}$ & \multicolumn{5}{|l|}{\begin{tabular}{|l|}
0.46 \\
0.376 \\
0.314
\end{tabular}} & \multicolumn{5}{|l|}{$\begin{array}{l}0.34 \\
0.277 \\
0.171\end{array}$} \\
\hline
\end{tabular}

Si conc.: Silicon foliar application. Bio. : Biofertilization Azoto: Azotobacter chroococcum, PDB: Bacillus megatherium.

The stimulatory effects might be attributed to the activation of the growth of microflora including many plant growth stimulators, biological nitrogen fixation and increasing available phosphorous which improve plant growth (Shehata and El-Khawas, 2003). Moreover, among the advantages of using silicon in agriculture are a reduction in water stress, since this element reduces transpiration, an increase in photosynthetic efficiency by maintaining leaves more erect and rigid and with more light interception; and an increase in the resistance to diseases, pests, cold, salinity and toxicity caused by an excess of Al, Mn and Fe. Many of these benefits are attributed to a layer of silicon accumulating beneath the cuticle (Epstein, 1999, Mauad et al., 2003 and Tahir et al., 2006). The highest significant effects on growth parameters were recorded with mixing biofertilization and silicon foliar application $(1000 \mathrm{mg} / \mathrm{L}$.) interaction treatments.

The stimulative effect of both biofertilizers used and silicon foliar application on growth parameters of sunflower are in accordance with the results obtained by Mahmoud and Amara (2000), Shaukat et al. (2006) and Yasari \& Patwarahan (2007).

Egypt. J. Soil Sci. 53, No. 4 (2013) 


\section{Yield and yield attributes}

The data in Table 4 showed that head diameter, weight of 100 -seed, seed and straw yields $(\mathrm{Kg} / \mathrm{fed})$ were significantly influenced by the biofertilization, silicon foliar application and their interaction treatments.

Yield and yield attributes increased ascendingly with increasing silicon foliar application up to $1000 \mathrm{mg} / \mathrm{l}$. (Fig.1,2) Similar results were obtained by Shengyi et al. (1999), Kumbhar and Saavant (1999), Filho et al. (2005), Singh et al. (2007), Gunes et al. (2008) and Muhammad et al. (2013).

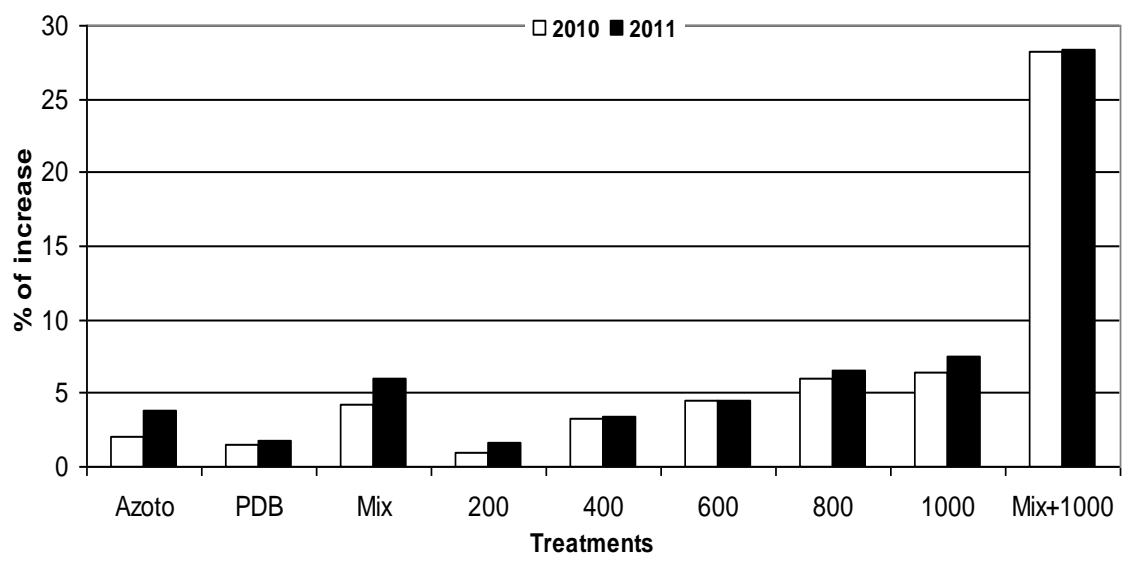

Fig.1. Effect of silicon foliar application and biofertilization on $\%$ of increase for sunflower seed yield (2010 and 2011 growing seasons).

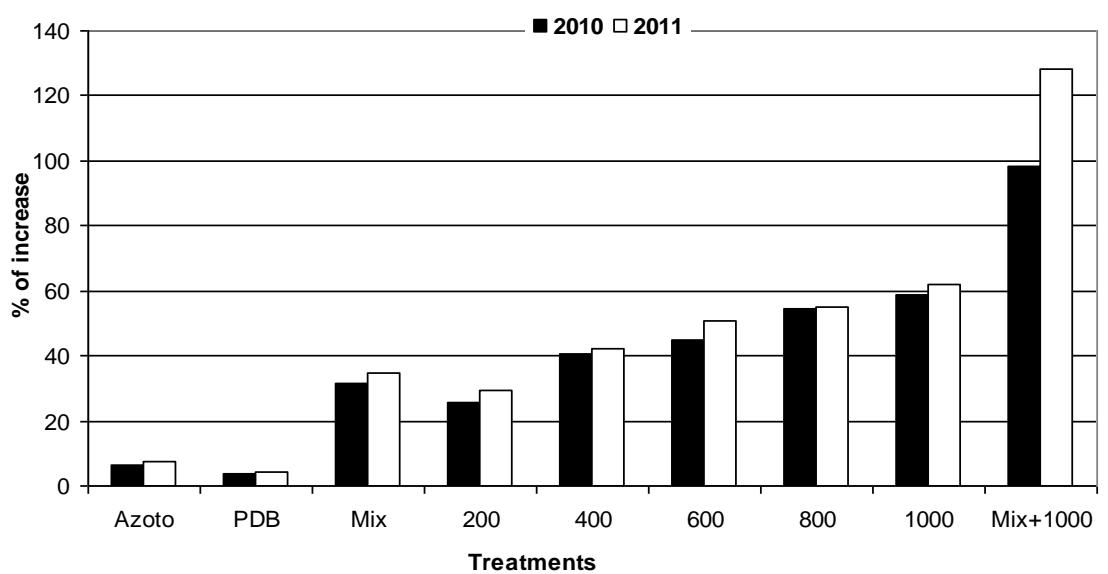

Fig. 2. Effect of silicon foliar application and biofertilization on $\%$ of increase for sunflower straw yield (2010 and 2011 growing seasons).

Egypt. J. Soil Sci. 53, No.4 (2013) 
In this respect, biofertilization treatments had significant effects on the studied yield criteria. Mixed biofertilization treatment showed synergistic effect compared with single treatment. It was clearly noticed that, A.chrococcum treatment recorded higher values compared with B. megatherium treatment. The $\%$ of increase than control with A.chrococcum treatment was $6 \%$ and $7 \%$ for seed yield and $2 \%$ and $4 \%$ for straw yield compared with PDB treatment was 3.8\% and $4 \%$ for seed yield and $1.5 \%$ and $1.8 \%$ for straw yield at first and second season respectively. The superiority of A.chroococcum may be due to its important role in Sunflower generative growth and therefore a significant increase in 100-seed weight which reflected on seed and straw yields. Kader et al. (2000) reported that A.chroococcum increase the available nitrogen in the soil which could enhance seed number in plant.

Remarkable influence of the interaction between silicon foliar application levels and biofertilization treatments with all yield and yield components was obtained (Table 4 and Fig.1,2). In this respect, interaction of silicon at 1000 $\mathrm{mg} / \mathrm{L}$ with mixed biofertilization treatment recorded the highest values being (23.5 and 24.9), (6.39 and 6.56), (983 and 1143) and (2072 and 2164.1) each for head diameter, weight of 100 -seed, seed and straw yields $(\mathrm{Kg} / \mathrm{fed})$ through $1^{\text {st }}$ and $2^{\text {nd }}$ season respectively. This significant increase in yield and yield components due to biofertilization along with silicon application treatments had synergistic effects on subsequent plant growth and stimulate microbial activities beneficial to plant growth and yield.

The stimulatory effects of biofertilizers on yield and yield components might be attributed to its efficiency in supplying the growing plant with biologically fixed nitrogen, dissolved immpolized phosphorus and produced phytohormones, which could stimulate nutrient absorbtion as well as photosynthesis process which subsequently increased plant growth and yield .Additionally, these results may be due to silicon generally stimulated leaves surface area, number of leaves/plant and dry matter of sunflower plants (Table 3 and 4) and this in turn increased photosynthetic areas and activity also, dry matter accumulation in seeds which were reflected in yield and yield attributes. The increments in sunflower yield and its components are in agreement with those of Saleh et al. (2004), Awad (2004) and Gunes et al. (2008). 
EFFECT OF BIOFERTILIZATION AND SILICON FOLIAR...

TABLE 4. Effect of silicon foliar application and biofertilization on growth traits of sunflower after 60 days from sowing (2010 growing season).

\begin{tabular}{|c|c|c|c|c|c|c|c|c|c|c|}
\hline \multirow{2}{*}{ Silicon } & \multicolumn{5}{|c|}{ Head diameter $(\mathrm{cm}) 1^{\text {st }}$ season } & \multicolumn{5}{|c|}{ Head diameter $(\mathrm{cm}) 2^{\text {nd }}$ season } \\
\hline & Cont. & Azoto & & Cont. & Azoto & & Cont. & Azoto & & Cont. \\
\hline 0 & 12.7 & 13.6 & 13.2 & 15.1 & 13.7 & 12.9 & 14.3 & 13.7 & 16 & 14.2 \\
\hline 200 & 13.2 & 15.8 & 14.9 & 16.2 & 15 & 13.8 & 16.5 & 15.7 & 18.7 & 16.2 \\
\hline 400 & 14.6 & 16.5 & 15.8 & 18.3 & 16.3 & 14.9 & 17.2 & 16.5 & 20 & 17.2 \\
\hline 600 & 14.9 & 17.9 & 17 & 19.6 & 17.4 & 15.5 & 19.4 & 18.2 & 21.2 & 18.6 \\
\hline 800 & 15.3 & 18.9 & 17.6 & 21 & 18.2 & 15.9 & 19.9 & 19.3 & 23.2 & 19.6 \\
\hline 1000 & 15.8 & 20.4 & 19.5 & 23.5 & 19.8 & 16.4 & 22 & 21.7 & 24.9 & 21.3 \\
\hline Mean & 14.4 & 17.2 & 16.3 & 19 & 16.7 & 14.9 & 18.2 & 17.5 & 20.7 & 17.8 \\
\hline $\begin{array}{l}\text { L.S.D. } \\
(\% \text { 0.05) } \\
\text { Silicon } \\
\text { con. Bio. } \\
\text { interaction }\end{array}$ & \multicolumn{5}{|l|}{$\begin{array}{l}0.305 \\
0.248 \\
2.130\end{array}$} & \multicolumn{5}{|l|}{$\begin{array}{l}0.246 \\
0.201 \\
2.404\end{array}$} \\
\hline \multicolumn{6}{|c|}{ Weight of 100 seed $(\mathrm{g}) 1^{s t}$ season } & \multicolumn{5}{|c|}{ Weight of 100 seed $2^{\text {nd }}$ season } \\
\hline 0 & \begin{tabular}{|l|}
4 \\
\end{tabular} & 4.2 & 4.1 & 4.5 & 4.2 & 4.1 & 4.2 & 4.3 & 4.7 & 4.3 \\
\hline 200 & 4.1 & 4.5 & 4.3 & 4.9 & 4.5 & 4.4 & 4.8 & 4.5 & 5.4 & 4.8 \\
\hline 400 & 4.6 & 5.1 & 4.7 & 5.2 & 4.9 & 4.6 & 5.3 & 4.9 & 5.7 & 5.1 \\
\hline 600 & 4.7 & 5.3 & 4.8 & 5.5 & 5.1 & 4.9 & 5.6 & 5.1 & 5.9 & 5.4 \\
\hline 800 & 5 & 5.6 & 5.2 & 6.2 & 5.5 & 5.2 & 5.9 & 5.6 & 6.5 & 5.8 \\
\hline 1000 & 5.3 & 5.9 & 5.7 & 6.4 & 5.8 & 5.7 & 6.1 & 6.2 & 6.6 & 6.2 \\
\hline Mean & 4.7 & 5.1 & 4.8 & 5.5 & 5 & 4.9 & 5.3 & 5.1 & 5.8 & 5.3 \\
\hline $\begin{array}{l}\text { L.S.D } \\
\text { Silicon } \\
0.05 \% \\
\text { Bio. } \\
\text { nteraction }\end{array}$ & \multicolumn{5}{|l|}{$\begin{array}{l}0.0305 \\
0.028 \\
0.074\end{array}$} & \multicolumn{5}{|l|}{$\begin{array}{l}0.062 \\
0.050 \\
0.098\end{array}$} \\
\hline \multirow{2}{*}{\multicolumn{6}{|c|}{ Seed yield $\mathrm{kg} / \mathrm{fed}$. }} & \multicolumn{5}{|c|}{ Seed yield $\mathrm{kg} / \mathrm{fed} . \quad 2^{\text {nd }}$ season } \\
\hline 0 & & & 514 & 650 & 546.5 & 513 & 538 & 522 & 674 & 561.8 \\
\hline 200 & 622 & 745 & 709 & 793 & 717.3 & 649 & 765 & 731 & 829 & 743.5 \\
\hline 400 & 696 & 813 & 781 & 844 & 783.5 & 713 & 838 & 815 & 875 & 810.3 \\
\hline 600 & 718 & 825 & 794 & 886 & 805.8 & 756 & 849 & 822 & 911 & 834.5 \\
\hline 800 & 766 & 837 & 723 & 920 & 811.5 & 778 & 864 & 839 & 965 & 861.5 \\
\hline 1000 & 785 & 852 & 841 & 983 & 865.3 & 811 & 885 & 862 & 1143 & 925.3 \\
\hline Mean & 680.3 & 766.5 & 727 & 846 & 755 & 703 & 789.8 & 765.2 & 899.5 & 789.5 \\
\hline $\begin{array}{l}\text { L.S.D } \\
\text { silicon } \\
0.05 \% \\
\text { Bio. } \\
\text { nteraction }\end{array}$ & \multicolumn{5}{|l|}{$\begin{array}{l}1.962 \\
1.602 \\
5.171\end{array}$} & \multicolumn{5}{|l|}{$\begin{array}{l}1.765 \\
1.441 \\
4.625\end{array}$} \\
\hline \multicolumn{6}{|c|}{ Straw yield kg/fed. } & \multicolumn{5}{|c|}{ Straw yield $\mathrm{kg} / \mathrm{fed} . \quad 2^{\text {nd }}$ season } \\
\hline 0 & 1612 & 1644 & 1636 & 1680 & 1643 & 1690 & 1754 & 1721 & 1791 & 1739 \\
\hline 200 & 1628 & 1672 & 1652 & 1728 & 1670 & 1717 & 1804 & 1783 & 1862 & 1791.5 \\
\hline 400 & 1664 & 1716 & 1704 & 1796 & 1720 & 1747 & 1849 & 1824 & 1940 & 1840 \\
\hline 600 & 1684 & 1780 & 1752 & 1872 & 1772 & 1766 & 1870 & 1845 & 1990 & 1867.8 \\
\hline 800 & 1708 & 1836 & 1804 & 1932 & 1820 & 1800 & 1930 & 1912 & 2114 & 1939 \\
\hline 1000 & 1716 & 1944 & 1900 & 2068 & 1907 & 1816 & 2041 & 2002 & 2169 & 2007 \\
\hline Mean & 1668.7 & 1765.3 & 1741.3 & 1846 & 1755.3 & 1756 & 1874.7 & 1847.8 & 1977.7 & 1864 \\
\hline $\begin{array}{l}\text { L.S.D } \\
\text { silicon } \\
0.05 \% \\
\text { Bio. } \\
\text { nteraction }\end{array}$ & \multicolumn{5}{|l|}{$\begin{array}{l}0.039 \\
0.285 \\
0.037\end{array}$} & \multicolumn{5}{|l|}{$\begin{array}{l}0.056 \\
0.033 \\
0.069\end{array}$} \\
\hline
\end{tabular}

Si conc.: Silicon foliar application.

PDB: Bacillus megatherium.

Bio. : Biofertilization Azoto: Azotobacter chroococcum,

Egypt. J. Soil Sci. 53, No.4 (2013) 
3. Oil percentage and oil yield

Data in Table 5 clarified that oil percentage and oil yield of sunflower were significantly affected by silicon foliar application, biofertilization treatments and their interaction in both seasons. It was be noticed that $2^{\text {nd }}$ season surpassed $1^{\text {st }}$ season.

TABLE 5. Effect of silicon foliar application and biofertilization on yield, yield components, Oil\% and Oil yield of sunflower (2010 and 2011 growing seasons).

\begin{tabular}{|c|c|c|c|c|c|c|c|c|c|c|}
\hline \multirow{2}{*}{\begin{tabular}{|r|} 
bio \\
Silicon
\end{tabular}} & \multicolumn{5}{|c|}{ Oil $\% 1^{s t}$ season } & \multicolumn{5}{|c|}{ Oil\% $2^{\text {nd }}$ season } \\
\hline & Cont. & Azoto & PDB & Mix & Mean & Cont. & Azoto & PDB & Mix & Mean \\
\hline 0 & 25.6 & 31.2 & 34.8 & 35.6 & 31.8 & 29.2 & 31.8 & 35.2 & 36.2 & 33.1 \\
\hline 200 & 30.4 & 31.9 & 36.5 & 37.2 & 34 & 31.6 & 32.1 & 37.6 & 38.1 & 34.85 \\
\hline 400 & 31.8 & 32.1 & 37.5 & 37.9 & 34.825 & 32.1 & 32.4 & 37.9 & 38.2 & 35.15 \\
\hline 600 & 32.1 & 33 & 38.1 & 38.5 & 35.425 & 32.5 & 33.7 & 38.3 & 38.9 & 35.85 \\
\hline 800 & 32.6 & 34.2 & 38.5 & 38.9 & 36.05 & 33 & 34.9 & 38.9 & 39.3 & 36.525 \\
\hline 1000 & 32.8 & 35.9 & 39.3 & 39.7 & 36.925 & 33.3 & 36.1 & 39.5 & 39.8 & 37.175 \\
\hline Mean & 30.9 & 33.1 & 37.5 & 38 & 34.8 & 32 & 33.5 & 37.9 & 38.4 & 35.4 \\
\hline $\begin{array}{l}\text { L.S.D } \\
\text { Silicon } \\
0.05 \% \\
\text { Bio. } \\
\text { interaction }\end{array}$ & \multicolumn{5}{|l|}{$\begin{array}{l}0.212 \\
0.173 \\
0.629\end{array}$} & \multicolumn{5}{|l|}{$\begin{array}{l}0.237 \\
0.194 \\
0.773\end{array}$} \\
\hline \multicolumn{6}{|c|}{ Oil yield $\mathrm{kg} / \mathrm{fed} 1^{\text {st }}$ season } & \multicolumn{5}{|c|}{ Oil yield $\mathrm{kg} /$ fed $2^{\text {nd }}$ season } \\
\hline 0 & 310 & 34.9 & 367 & 374 & 271.5 & 319 & 358 & 375 & 389 & 360.3 \\
\hline 200 & 341 & 378 & 394 & 412 & 381.3 & 359 & 383 & 403 & 418 & 390.8 \\
\hline 400 & 365 & 391 & 426 & 438 & 405 & 376 & 410 & 435 & 445 & 416.5 \\
\hline 600 & 391 & 415 & 448 & 492 & 436.5 & 397 & 421 & 456 & 528 & 450.5 \\
\hline 800 & 413 & 424 & 456 & 514 & 451.8 & 421 & 435 & 481 & 539 & 469 \\
\hline 1000 & 422 & 433 & 472 & 548 & 468.8 & 429 & 442 & 496 & 573 & 485 \\
\hline Mean & 373.7 & 346 & 427.2 & 463 & 402.5 & 383.5 & 408.6 & 441 & 482 & 428.7 \\
\hline $\begin{array}{l}\text { L.S.D } \\
\text { Silicon } \\
0.05 \% \\
\text { Bio. } \\
\text { interaction }\end{array}$ & \multicolumn{5}{|l|}{$\begin{array}{l}1.711 \\
1.397 \\
4.347\end{array}$} & \multicolumn{5}{|l|}{$\begin{array}{l}1.765 \\
1.44 \\
4.625\end{array}$} \\
\hline
\end{tabular}

Oil \% and oil yield had a gradually increasing as silicon concentration increased. The promoting effect of biofertilization treatments (Single or mixed) extended to both oil yield and oil \%, As a result to the ability of phosphate dissolving bacteria (B.megatherium) to solubilize phosphate and increase its availability for plant metabolism, it exhibited superiority effect in oil yield and oil \% compared with A.chroococcum, this results in accordance with Ogbo (2010).

In this respect, sunflower plants which received the different concentrations of silicon up to $1000 \mathrm{mg} / \mathrm{l}$ with mixtures of A.chroococcum and B. megatherium showed superiority in oil \% and oil yield as compared with other concentrations of silicon and single biofertilization treatments.

Egypt. J. Soil Sci. 53, No. 4 (2013) 
Moreover, the highest values of seed oil percentage and oil yield (Kg/fed) were recorded from sunflower plants spraying with silicon at $1000 \mathrm{mg} / \mathrm{L}$ in combination with mixed biofertilization treatment being $39.7,39.8 \%$ and $548,573(\mathrm{Kg} / \mathrm{fed})$ each for oil \% and oil yield respectively, in both seasons as shown in (Table 5, Fig. 3), such significant increase due to improvement in translocation of assimilates. Different studies indicated positive effect of silicon application on the plant growth and development including enhanced pollination, increase dry biomass and final yield (Korndorfer and Lepsch, 2001 and Muhammad et al., 2013).
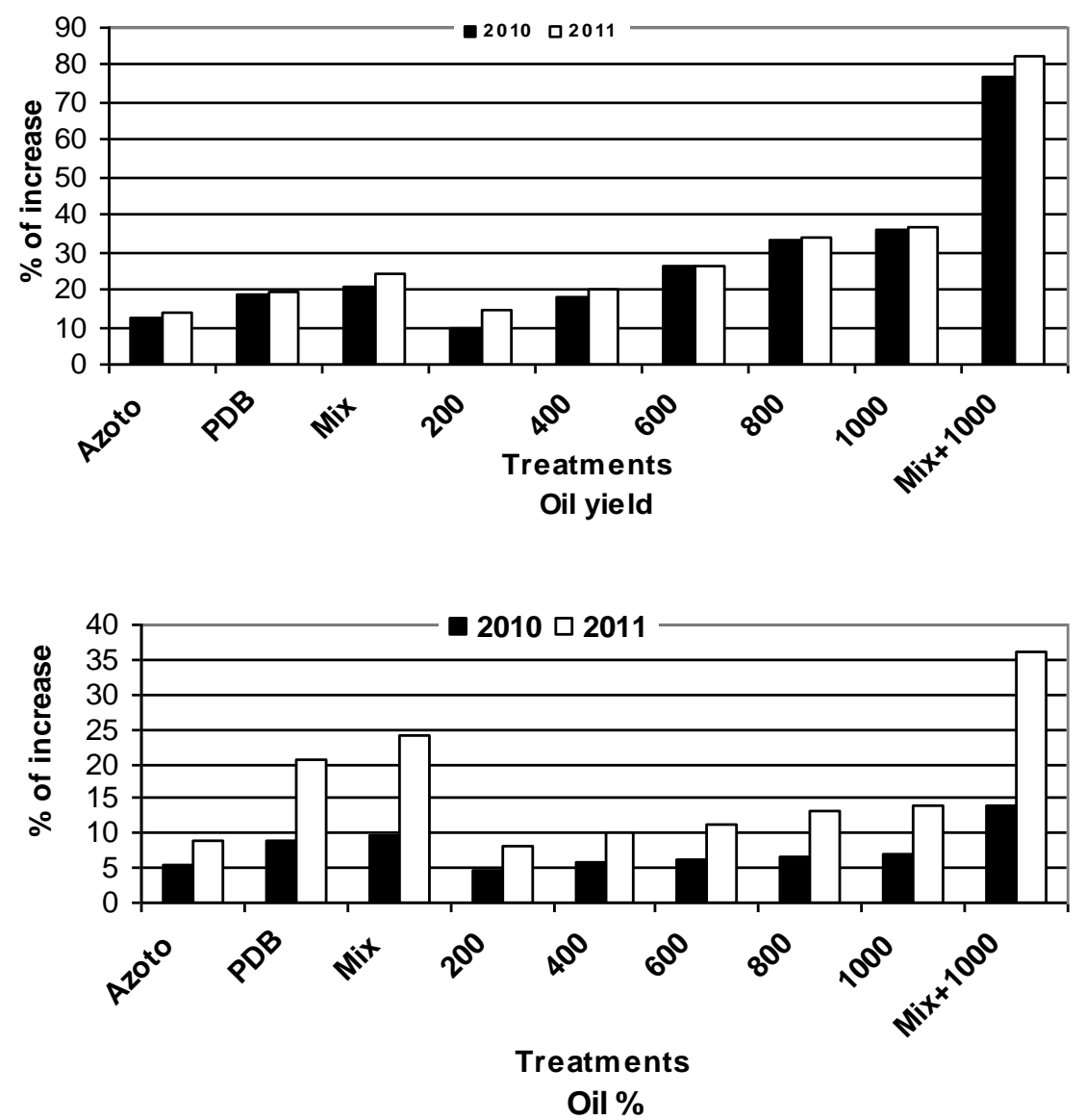

Fig. 3. Effect of silicon foliar application and biofertilization on $\%$ of increase sunflower oil yield and Oil \% (2010 and 2011 growing seasons).

\section{Effect of biofertilization and silicon on soil microbial analysis}

\subsection{General microbial activities}

4.1.1: Total microbial counts: Initial total microbial counts before cultivation were 19 and $23 \times 10^{5} \mathrm{cfu} / \mathrm{g}$ dry soil during two seasons, respectively (Table 6). 
TABLE 6. Effect of silicon foliar application and biofertilization on $\mathrm{CO}_{2}$ evolution ( $\mathrm{mg} \mathrm{CO} / 100 \mathrm{~g}$ dry soil $/ 24 \mathrm{hr}$ ), total microbial counts $\times 10^{5} \mathrm{cfu} / \mathrm{g}$ dry soil, in sunflower rhizosphere $(2010,2011$ growing season).

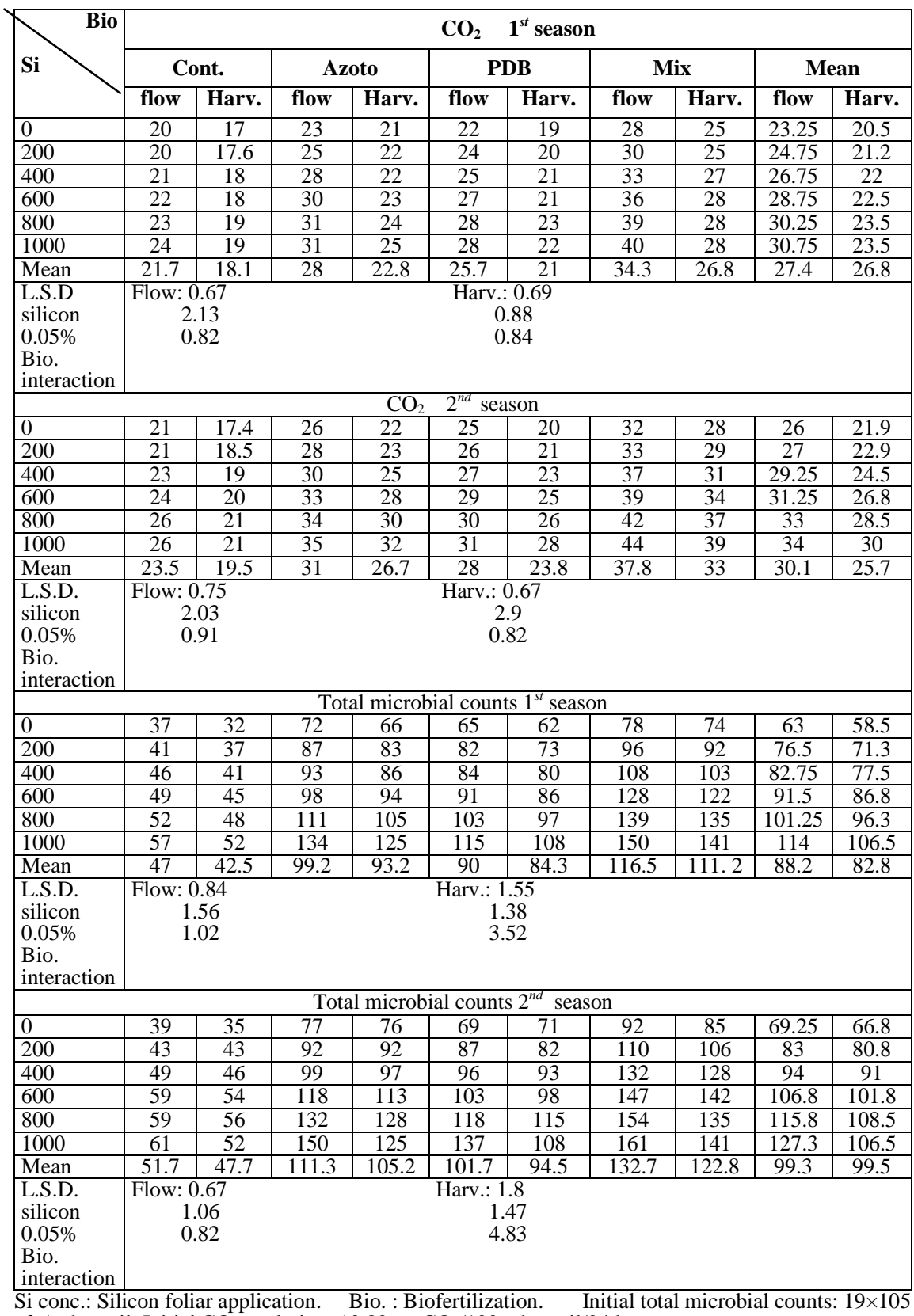

$\mathrm{cfu} / \mathrm{g}$ dry soil, Initial $\mathrm{CO}_{2}$ evolution: $10.82 \mathrm{mg} \mathrm{CO}_{2} / 100 \mathrm{~g}$ dry soil $/ 24 \mathrm{hr}$.

Egypt. J. Soil Sci. 53, No. 4 (2013) 
Generally the counts at flowering stage of sunflower growth were higher than those of harvesting stage and all the treatments exceeded the control. Total microbial counts slightly increased with increasing silicon concentrations which might be due to silicon foliar spray enhance plant growth, the simulative effect of plant rhizosphere on the adjacent microorganisms leads to increase total microbial counts. Another increase in counts was associated with the use of biofertilizers either in the form of single or mixed treatment as shown in Fig.4. The enhancement effect in microbial activity is a good parameter for many soil improvement indiccators. For example A.chroococcum and B. megatherium produce growth promoting substances, biological nitrogen fixation, organic acids production and other enzymatic activities which enhance plant growth and proliferate lateral roots and root hairs which increase nutrient absorbing surface (El-Shazly, 2010). The highest counts were associated with mixed treatment (A.chroococcum and B. megatherium) and silicon foliar application at 1000 $\mathrm{mg} / \mathrm{L}$ to be 154 and $161 \times 10^{5} \mathrm{cfu} / \mathrm{g}$ dry soil at flowering stage of sunflower during two seasons, respectively. These results are compatible with those obtained by (Ashrafuzzaman et al., 2009) who reported that, inoculation with the plant growth promoting rhizobacteria (Azotobcter, Bacillus megaterium) had stimulation effect on the population of rhizosphere microorganism and increased their numbers by more than $50 \%$ at the end of the experiment comparing with the number recorded before planting.

4.1.2: $\mathrm{CO}_{2}$ evolution : The generation of carbon dioxide $\left(\mathrm{CO}_{2}\right)$ was determined as an indication of the biological activity in plant rhizosphere. Results in Table 6 clearly showed that a slight increase in microbial activity as a result of increasing foliar application of silicon up to $1000 \mathrm{mg} / \mathrm{l}$ due to indirect enhancement effect on microbial activity in rhizosphere of cultivated plant. Inoculation with both biofertilizers (A.chroococcum and B. megatherium) individual or mixed encourage the microbial activity in rhizosphere of sunflower plant. Interaction of biofertilization with silicon foliar application gave higher rate of $\mathrm{CO}_{2}$ evolution than single treatment. The highest $\%$ of increase than control for mixed biofertilization and silicon foliar application $(1000 \mathrm{mg} / \mathrm{l})$ treatment being $105 \%$ and $109 \%$ and $67 \%$ and $124 \%$ at flowering stage of sunflower during two seasons, respectively (Fig.4). Data of $\mathrm{CO}_{2}$ evolution were almost in harmony with those of total microbial counts discussed before (Visser and Dennis, 1992). 


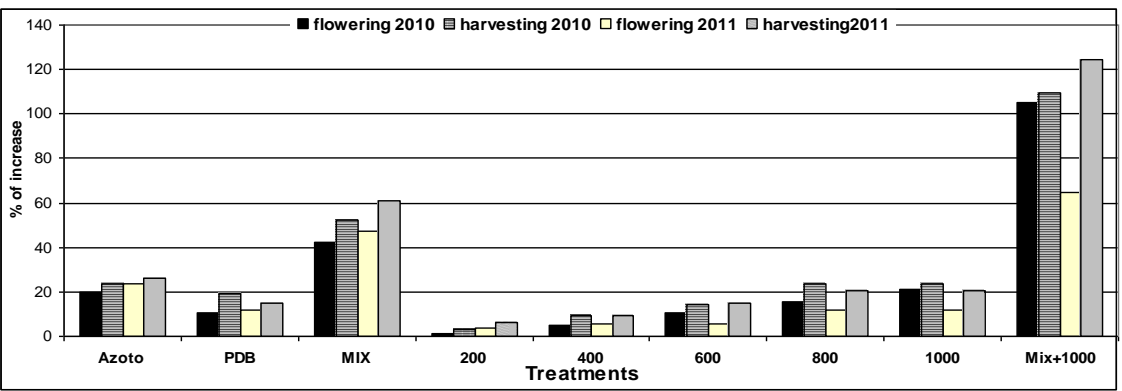

A

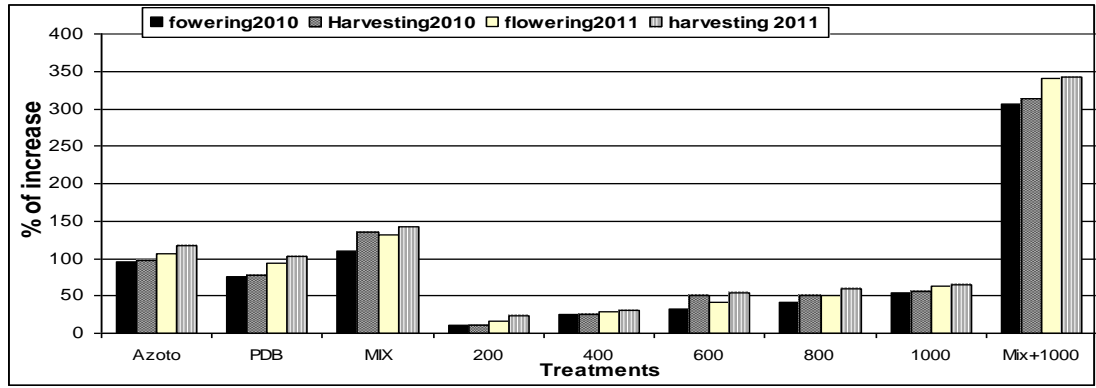

B

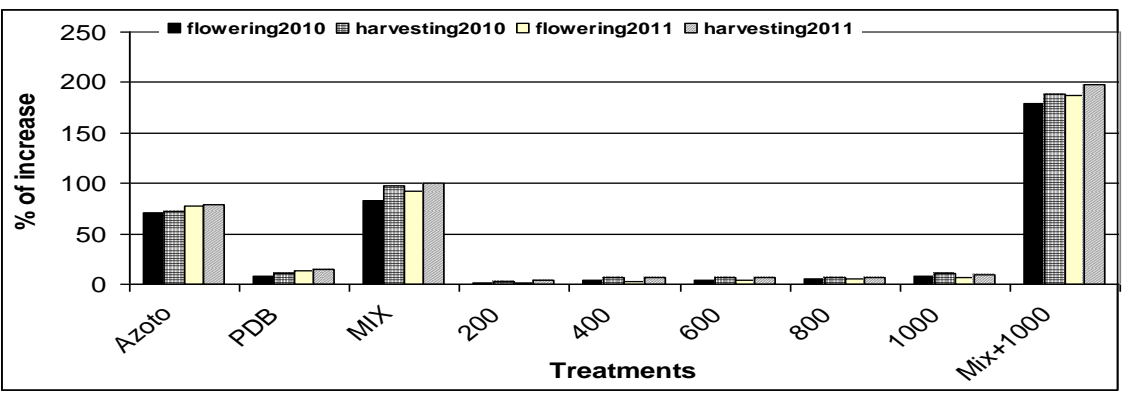

C

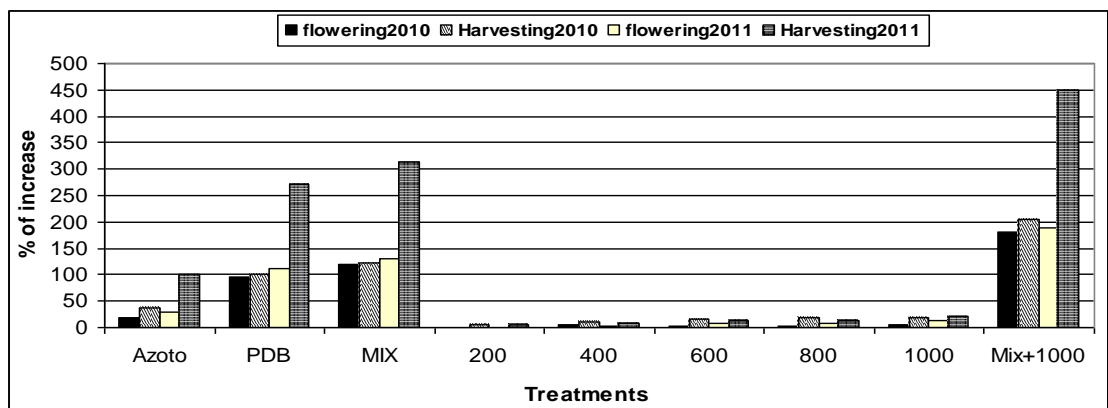

D

Fig. 4. \% of increase than control for $\mathrm{A}-\mathrm{CO}_{2}$ evolution , B-total microbial counts $\times$ C-Azotobacter counts D- Phosphate dissolving bacteria .

Egypt. J. Soil Sci. 53, No. 4 (2013) 


\subsection{Specific microbial activities}

4.2.1 Azotobacter densities: Represented data in Table 6 recorded improvement in azotobacters counts by different treatments as compared with control. The indirect role of silicon foliar application on microbial activity in rhizosphere of treated plant reflected on Azotobacter densities in soil. Inoculation with biofertilizers with A.chroococcum and B. megatherium (individually or mixed) had stimulating effect on Azotobacter counts in rhizosphere. Synergistic effects of biofertilizers application and silicon spray enhances Azotobacter counts in soil (Fig. 4) .

Interaction of A.chroococcum and B. megatherium with silicon foliar application at $1000 \mathrm{mg} / \mathrm{L}$ in mixed treatment recorded the highest counts and highest \% of increase than control to be 67 and $70 \times 10^{4} \mathrm{cfu} / \mathrm{g}$ dry soil for counts and $187 \%$ and $189 \%$ for $\%$ of increase at flowering stage of sunflower during two seasons, respectively. The promoting effect due to application of $A$. chroococcum not only due to the nitrogen fixation but also to the production of plant growth promoting substances, production of amino acids, organic acids, vitamins and antimicrobial substances as well, which increase soil fertility, microbial community and plant growth (Revillas et al., 2005).

4.2.2. Phosphate dissolving bacteria (PDB): Initial counts of PDB before cultivation were 4.2 and $6.0 \times 10^{2} \mathrm{cfu} / \mathrm{g}$ dry soil during two seasons, respectively (Table 7). However their counts tended to increase in all treatments rather than the control. Significant increases were recorded at flowering compared to harvesting stages of plant growth. It was noticed that, the enhancement effect with silicon foliar application up to $1000 \mathrm{mg} / \mathrm{l}$ on counts of PDB was slightly compared with biofertilizers application (single or mixed). The highest counts and $\%$ of increase than control were recorded in mixed biofertilization treatment and silicon foliar application at $1000 \mathrm{mg} / \mathrm{L}$ to be 25.9 and $29 \times 10^{2} \mathrm{cfu} / \mathrm{g}$ dry soil for counts and $181.5 \%$ and $208 \%$ for $\%$ of increase at flowering stage of sunflower during two seasons, respectively (Fig. 4). A similar trend was recorded by Khan et al. (2006).

\subsection{Enzymatic activity}

4.3.1. Dehydrogenase enzyme: Data in Table 8 showed the determination of enzymatic activities in rhizosphere of sunflower plants. Dehydrogenase activity (DHA) represents the energy transfer, therefore, it is considered as an index of overall microbial activity in the soil. Represented data recorded that silicon foliar application recorded lower values for DHA activity compared with biofertilization treatments. Interaction treatment of biofertilization with silicon at concentration $1000 \mathrm{mg} / \mathrm{l}$ recorded the highest DHA activity. This may be due to that A.chroococcum and B.megatherium played an important role as plant growth promoting rhizobacteria via $\mathrm{N}_{2}$ fixation and P-solubilization (El-Howeity et al., 2003 and Muthukumar \& Udaiyan, 2006). This might led to accumulate available nutrients and stimulate the microorganisms in soil rhizosphere. 
TABLE 7. Effect of silicon foliar application and biofertilization on Azotobacter densities $\times 10^{4} \mathrm{cfu} / \mathrm{g}$ dry soil and phosphate dissolving bacteria counts $\times 10^{2}$ cfu/g dry soil , in sunflower rhizosphere $(2010,2011$ growing season $)$.

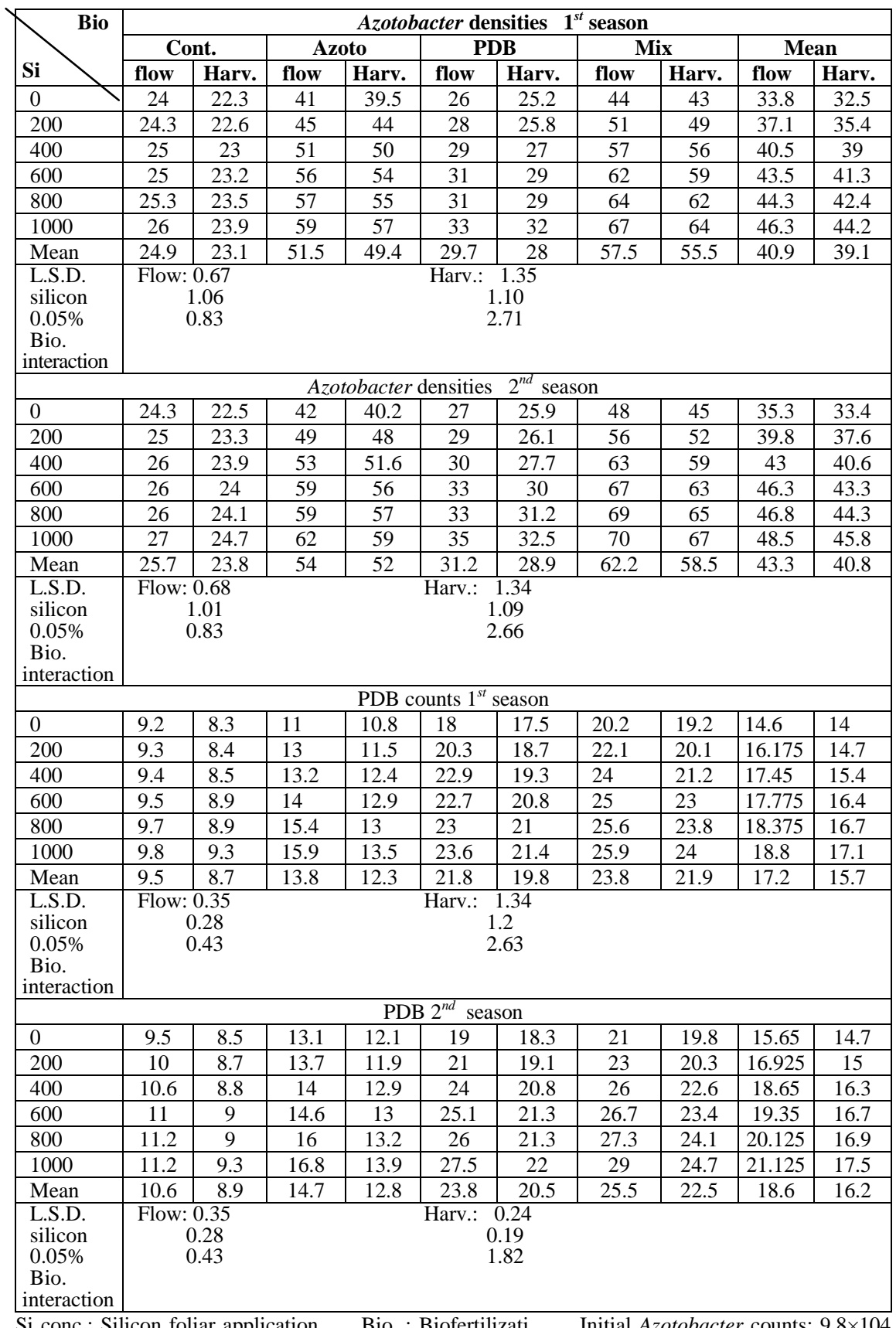

$\mathrm{Si}$ conc. Silicon foliar application $\quad$ Bio. : Biofertilizati. Initial Azotobacter counts: $9.8 \times 104$ $\mathrm{cfu} / \mathrm{g}$ dry soil. Initial Phosphate dissolving bacteria: $4.2 \times 102 \mathrm{cfu} / \mathrm{g}$ dry soil.

Egypt. J. Soil Sci. 53, No. 4 (2013) 
EFFECT OF BIOFERTILIZATION AND SILICON FOLIAR...

TABLE 8. Effect of silicon foliar application and biofertilization on dehydrogense activity $\left(\mu \mathrm{IDHA} / \mathrm{g}\right.$ dry soil), nitrogenase activity $\left(\mu \mathrm{MC}_{2} \mathrm{H}_{4} \mathrm{~kg} / \mathrm{hr}\right)$ and phosphatase (mgphenol/g soil/24hr) in sunflower rhizosphere $(2010,2011$ growing season).

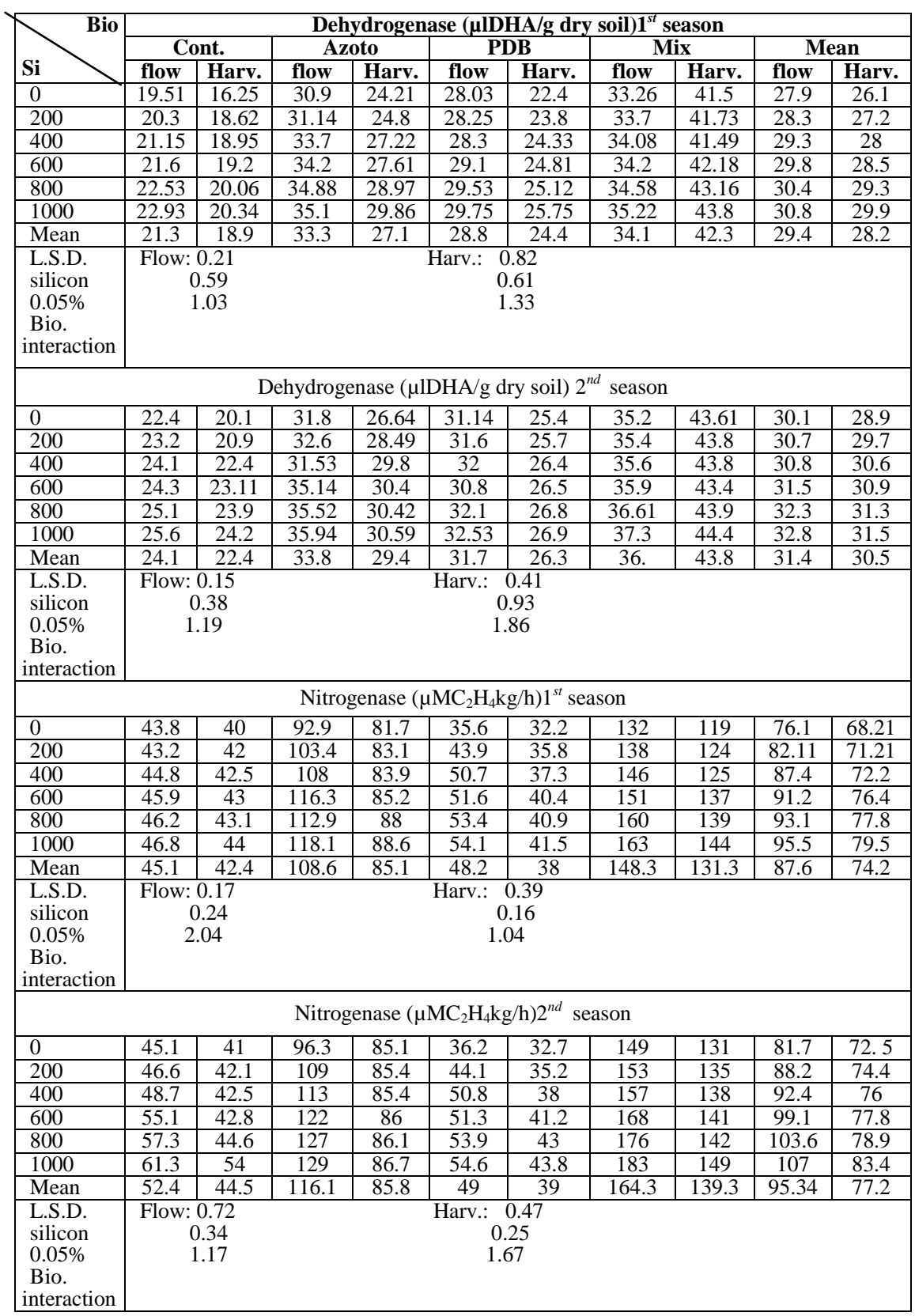

Egypt. J. Soil Sci. 53, No.4 (2013) 
TABLE 8. Contd.

\begin{tabular}{|c|c|c|c|c|c|c|c|c|c|c|}
\hline \multirow{3}{*}{$\mathrm{Si}^{\mathrm{Bio}}$} & \multicolumn{10}{|c|}{ Phosphatase (mgphenol/g soil/24hr) $1^{\text {st }}$ season } \\
\hline & \multicolumn{2}{|c|}{ Cont. } & \multicolumn{2}{|c|}{ Azoto } & \multicolumn{2}{|c|}{ PDB } & \multicolumn{2}{|c|}{ Mix } & \multicolumn{2}{|c|}{ Mean } \\
\hline & flow & Harv. & flow & Harv. & flow & Harv. & flow & Harv. & flow & Harv. \\
\hline 0 & 0.41 & 0.39 & 0.57 & 0.52 & 0.48 & 0.46 & 0.71 & 0.69 & 0.5 & 0.51 \\
\hline 200 & 0.43 & 0.4 & 0.66 & 0.6 & 0.55 & 0.54 & 0.8 & 0.78 & 0.61 & 0.58 \\
\hline 400 & 0.44 & 0.4 & 0.71 & 0.63 & 0.58 & 0.58 & 0.84 & 0.81 & 0.64 & 0.61 \\
\hline 600 & 0.4 & 0.42 & 0.78 & 0.66 & 0.62 & 0.63 & 0.87 & 0.82 & 0.67 & 0.63 \\
\hline 800 & 0.46 & 0.43 & 0.83 & 0.68 & 0.71 & 0.65 & 0.9 & 0.85 & 0.73 & 0.65 \\
\hline 1000 & 0.48 & 0.47 & 0.83 & 0.68 & 0.75 & 0.68 & 0.93 & 0.86 & 0.75 & 0.67 \\
\hline Mean & 0.44 & 0.42 & 0.73 & 0.63 & 0.62 & 0.59 & 0.84 & 0.8 & 0.66 & 0.601 \\
\hline $\begin{array}{l}\text { L.S.D. } \\
\text { silicon } \\
0.05 \% \\
\text { Bio. } \\
\text { interaction }\end{array}$ & \multicolumn{6}{|c|}{$\begin{array}{r}\text { Flow:0.35 } \\
0.28 \\
0.43\end{array}$} & & & & \\
\hline \multicolumn{11}{|c|}{ Phosphatase (mg phenol/g soil/24hr) $2^{\text {nd }}$ season } \\
\hline 0 & 0.46 & 0.42 & 0.64 & 0.58 & 0.53 & 0.49 & 0.83 & 0.77 & 0.62 & 0.57 \\
\hline 200 & 0.46 & 0.43 & 0.69 & 0.63 & 0.57 & 0.53 & 0.88 & 0.81 & 0.65 & 0.6 \\
\hline 400 & 0.48 & 0.44 & 0.73 & 0.64 & 0.61 & 0.59 & 0.9 & 0.83 & 0.68 & 0.63 \\
\hline 600 & 0.49 & 0.46 & 0.77 & 0.69 & 0.67 & 0.62 & 0.91 & 0.84 & 0.71 & 0.65 \\
\hline 800 & 0.51 & 0.47 & 0.85 & 0.71 & 0.74 & 0.67 & 0.91 & 0.87 & 0.75 & 0.68 \\
\hline 1000 & 0.53 & 0.47 & 0.89 & 0.75 & 0.79 & 0.7 & 0.95 & 0.9 & 0.79 & 0.71 \\
\hline Mean & 0.49 & 0.45 & 0.76 & 0.67 & 0.66 & 0.6 & 0.9 & 0.84 & 0.7 & 0.64 \\
\hline $\begin{array}{l}\text { L.S.D. } \\
\text { silicon } \\
0.05 \% \\
\text { Bio. } \\
\text { interaction }\end{array}$ & \multicolumn{4}{|c|}{$\begin{array}{c}\text { Flow:0.24 } \\
0.57 \\
1.09\end{array}$} & arv.: & $\begin{array}{l}51 \\
27 \\
9\end{array}$ & & & & \\
\hline
\end{tabular}

4.3.2. Nitrogenase activity: Concerning nitrogenase activity was more pronounced at flowering stage and $2^{\text {nd }}$ season than harvesting stage and $1^{\text {st }}$ season. Similarly, lower variation in nitrogenase activity were recorded with silicon foliar application up to $1000 \mathrm{mg} / \mathrm{l}$ while, biofertilization treatments (individually or mixed) recorded significant differences in nitrogenase activity, synergistic effect of mixed biofertilization with silicon foliar application $1000 \mathrm{mg} / \mathrm{l}$ showed highest figure for nitrogenase activity (Table 8). Many investigators demonstrated the positive effect of dual inoculation with $\mathrm{N}_{2}$-fixer and P-solubilizer on $\mathrm{N}_{2}$-ase activity (El- Komy, 2005).

4.3-3-Phosphatase activity: Some free living microorganisms in soil have capability to produce extracellular enzymes such as phosphatase (George et al., 2002). This enzyme is able to mineralize organic phosphates into inorganic phosphates that provides high phosphate for plant. The results in Table 8 clearly showed that, phosphatase activity recorded significant increase at flowering stage compared to harvesting stage of plant growth. Silicon foliar application caused slight increase in phosphatase activity. While, biofertilizers (single or mixed) recorded significant differences in phosphatase activity. Mixed

Egypt. J. Soil Sci. 53, No. 4 (2013) 
biofertilization with silicon at concentration $1000 \mathrm{mg} / \mathrm{l}$ recorded the highest phosphatase activity (Table 8 ).

\section{Economic evaluation}

In order to evaluate the results obtained, the investment ratio for every treatment was calculated by the ratio of total gain to its total costs/fed. The total costs in L.E. for different agricultural practices under the experimental conditions recorded $1740 \mathrm{LE} / \mathrm{fed}$. For treatment with Silicon and Biofertilizers, 1700LE/fed. For treatment with silicon only, 1690 for biofertilization treatment only and 1650 for control (Table 9).

The investment ratios (IR) of sunflower crop were recorded in Table 10. The results showed that silicon foliar spray with biofertilizers application increased IR. The highest ratio was obtained under with mixed treatment (A.chroococcum and B. megatherium) and silicon foliar application at $1000 \mathrm{mg} / \mathrm{L}$. compared with control.

From Table 10 it could be noticed that, for biofertilization treatments mixed treatment with A.chrococcum and B.megatherium increased IR followed by individual treatment with A.chrococcum only, then PDB only. In order to evaluate the effect of silicon foliar spray, IR increased with increasing silicon concentration. In general, mixed treatment with both biofertilizers and silicon foliar spray $1000 \mathrm{mg} / \mathrm{L}$ gave the highest values for seed, straw and IR as well.

TABLE 9. The price in L.E. for different agriculture inputs under experimental conditions.

\begin{tabular}{|l|c|}
\hline \multicolumn{1}{|c|}{ Items } & Price (L.E.) \\
\hline Land Preparation & 150 \\
Seed and Cultivation & 300 \\
Irrigation & 200 \\
Organic manuring & 300 \\
Silicon & 50 \\
Biofertilizers & 40 \\
Harvest Crop & 200 \\
transportation & 200 \\
Rent & 400 \\
\hline Total & 1840 \\
\hline
\end{tabular}


TABLE 10 . Investement ratios of sunflower crop under silicon and biofertilization treatments.

\begin{tabular}{|c|c|c|c|c|c|}
\hline \multirow{2}{*}{ Treatments } & \multicolumn{3}{|c|}{ Gain LE./fed } & \multirow{2}{*}{ Cost } & \multirow{2}{*}{ IR } \\
\hline & Seed & Straw & Total & & \\
\hline Control & 1089 & 644.8 & 1733.8 & 1750 & -0.991 \\
\hline Azotobacter & 1159.4 & 657.6 & 1817 & 1750 & 1.038 \\
\hline PDB & 1130.8 & 654.4 & 1785.2 & 1790 & -0.997 \\
\hline Mix & 1430 & 672 & 2102 & 1790 & 1.174 \\
\hline Silicon 200 & 1368.4 & 651.2 & 2019.6 & 1800 & 1.122 \\
\hline Silicon $200+\mathrm{Az}$ & 1639 & 668.8 & 2307.8 & 1840 & 1.254 \\
\hline Silicon 200+PDB & 1559.8 & 660.8 & 2220.6 & 1840 & 1.207 \\
\hline Silicon 200+mix & 1744.6 & 691.2 & 2435.8 & 1840 & 1.324 \\
\hline Silicon 400 & 1531.2 & 665.6 & 2196.8 & 1800 & 1.22 \\
\hline Silicon $400+A z$ & 1788.6 & 686.4 & 2475 & 1840 & 1.345 \\
\hline Silicon 400+PDB & 1718.2 & 681.6 & 2399.8 & 1840 & 1.304 \\
\hline Silicon 400+mix & 1856.8 & 718.4 & 2575.2 & 1840 & 1.4 \\
\hline Silicon 600 & 1579.6 & 673.6 & 2253.2 & 1800 & 1.251 \\
\hline Silicon $600+A z$ & 1815 & 712 & 2527 & 1840 & 1.373 \\
\hline Silicon 600+PDB & 1746.8 & 700.8 & 2447.6 & 1840 & 1.33 \\
\hline Silicon $600+\operatorname{mix}$ & 1949.2 & 748.8 & 2698 & 1840 & 1.466 \\
\hline Silicon 800 & 1685.2 & 683.2 & 2368.4 & 1800 & 1.356 \\
\hline Silicon $800+\mathrm{Az}$ & 1841.4 & 734.4 & 2575.8 & 1840 & 1.4 \\
\hline Silicon $800+$ PDB & 1810.6 & 721.6 & 2532.2 & 1840 & 1.376 \\
\hline Silicon $800+\operatorname{mix}$ & 2037.2 & 772.8 & 2810 & 1840 & 1.527 \\
\hline Silicon 1000 & 1727 & 686.4 & 2413.4 & 1800 & 1.34 \\
\hline Silicon $1000+\mathrm{Az}$ & 1874.4 & 777.6 & 2652 & 1840 & 1.441 \\
\hline Silicon 1000+PDB & 1850.2 & 760 & 2610.2 & 1840 & 1.418 \\
\hline Silicon $1000+\operatorname{mix}$ & 2162.6 & 828.8 & 2991.4 & 1840 & 1.625 \\
\hline
\end{tabular}

\section{Conclusion}

It could be concluded from the abovementioned results that silicon and biofertilization contribute a considerable enhancement effect on sunflower plant growth as well as IR. For N-fixing bacteria as biofertilizers, Azotobacter chroococcum enhance the straw production of sunflower. On the other hand, The biofertilization with PDB ( B.megatherium var. phosphaticum) showed better results on plant growth when added in combination with Azotobacter chroococcum than when applied alone. So, it could be recommended for enhancing sunflower productivity by mixed biofertilization (Azotobacter chroococcum plus B.megatherium) in conjunction with spraying silicon at rate of $1000 \mathrm{mg} / \mathrm{L}$.

\section{References}

A.O.A.C. (1980) Association of Official Agriculture Chemists "Official Methods of Analysis", $13^{\text {th }}$ ed., Washington, DC, USA.

Abd El-Hafez, A.M. (1966) Some studies on acid producing microorganisms in soil and rhizosphere with special reference to phosphate dissolvers. Ph.D. Thesis, Fac. Agric., Ain Shams Univ., Cairo, Egypt.

Egypt. J. Soil Sci. 53, No. 4 (2013) 
Abdel-Malek, Y. and Ishac, Y.Z. (1968) Evaluation of methods used in counting Azotobacter. J. Appl. Bacteriol. 31: 267-275.

Abou-Khadrah, S.H., Mohamed, A.A.E., Gerges, N.R. and Diab, Z.M. (2002) Response of four sunflower hybrids to low nitrogen fertilizer levels and phosphorine biofertilizer. J. Agric. Res., Tanta Univ. 28 (1): 105-118.

Aduayi, E.A., Chude, V.O., Adebusuyi, B.A. and Olayiwola, S.O. (2002) Fertilizer use and management practices for crops in Nigeria. Federal Ministry of Agriculture and Rural Development Abuja, pp. 63-65, Nigeria.

Al-Aghabary, K., Zhu, Z.J. and Shi, Q.H. (2004) Influence of silicon supply on chlorophyll content, chlorophyll fluorescence, and antioxidative enzyme activities in tomato plants under salt stress. Journal of Plant Nutrition 27 : 1-15.

Ahmad, R., Zaheer, S. and Ismail, S. (1992) Role of silicon in salt tolerance of wheat (Triticum aestivum L.). Plant Sci. 85: 43-50.

Ashrafuzzaman, M., Farid, A.H.R.I.M., Anamul, H.M.D., Zahurul, I.S.M., Shahidullah, S.M. and Meon, S. (2009) Efficiency of plant growth-promoting rhizobacteria (PGPR) for the enhancement of rice growth. African Jornal of Biotechnology 8 (7): $1247-1252$.

Awad, M.M. (2004) Effect of nitrogen fertilization, farmyard manure and bio-fertilizers on yeild and yeild components of some sunflower hybrids in north delta region. Ph.D. Thesis, Agron. Dept., Fac. of Agric., Kafr El-Sheikh, Tanta Univ., Egypt.

Bélanger, R.R., Bowen, P.A., Ehret, D.L. and Menzies, J. G. (1995) Soluble silicon: Its role in crop and disease management of greenhouse crops. Plant Dis. 79: 329-336.

Bergey's Manual of Systemic Bacteriology (1984) Vol. (1), Krieg, N. R. and Holt, J. G. (Ed.), Genus Azospirillum. pp. 94-103 and Genus Azotobacter pp. 225-229.Vol (II) p. 1104-1139. Sneath, Ph.D. (Ed.), Genus Bacillus subtilis. Williams, Wilkins, Baltimore, USA.

Bremner, P. M. and Taha, M.A. (1966) Studies in potato agronomy, development and yield. J. Agric. Sci. 66 : 241-252.

Casida, L.E., Klein, D.A. and Santoro, T. (1964) Soil dehydrogenase activity. Soil Sci. 98: $371-378$.

Chen, C.H. and Lewin, J. (1968) Silicon as anutrient element for equisetum arvense. Can. J. Bot. 47: 125-131.

Chen, W., Yao, X., Cai, K. and Chen, J. (2010) Silicon alleviates drought stress of rice plants by improving plant water status, photosynthesis and mineral nutrient absorption. Biol. Trace. Elem. Res.

El-Howeity, M.A., Omar, M.N.A., Elshinnawi, M.M. and Aboel-Naga, S.A. (2003) Colonization pattern of some diazotrophs on wheat (Triticum aestivum) and maize (Zea mays) roots in vitro and in vivo experiments. $11^{\text {th }}$ Conf. of Microbiology, Cairo, Egypt, Oct. 12-14. 
El-Komy, H.M.A. (2005) Coimmobilization of Azospirillum lipoferum and Bacillus megaterium for successful phosphorus and nitrogen nutrition of wheat plants. Food Technol. Biotechnol. 43 (1): 19-27.

El-Shazly (2010) Employment of some effective microorganisms in improving sandy soil properties and productivity. Ph.D Thesis, Fac.Sci., Al-Azhar Univ.

Epstein, E. (1994) The anomaly of silicon in plant biology. Proc. Natl. Acad. Sci. 91: 11-17, U.S.A.

Epstein, E. (1999) Silicon Annual Review of Plant Physiology and Molecular Biology. 50: 641-664.

Fagbayide, J.A. and Adeoye, G.O. (1999) Sunflower growth and mineral uptake as influenced by fertilizer phosphorus. Tropical Oilseeds Journal 4: 21-28.

Fawe, A., Abou-Zaid, M., Menzies, J.G. and Bélanger, R.R. (1998) Silicon-mediated accumulation of flavonoid phytoalexins in cucumber. Phytopathology 88: 396-401.

Filho O.F.L., Sousa, P.G. and Tsai, S.M. (2005) Effect of silicon on varietal and growth response of wheat under hydroponic conditions. p. 132. $3^{\text {rd }}$ conference Silicon in Agriculture, 22-26 October, 2005, Uberlandia, Brazil.

George, T.S., Gregory, P. J., Wood, M., Read, D. and Buresh, R.J. (2002) Phosphates activity and organic acids in the rhizosphere of potential agro forestry species and maize. Soil Biology and Biochemistry 34: 1487-1494.

Gillman, J.H., Zlesak, D.C. and Smith, J.A. (2003) Applications of potassium silicate decrease black spot infection in Rosa hybrid. Department of Horticulture Sciences, University of Minnesota, 38: 1144-1147, USA.

Gomez, K.A. and Gomez, A.A. (1984) "Statistical Procedures for Agriculture Research", A Wiley- Inter Science Publication, John Wiley \& Sons, Inc. New York, USA.

Gong, H.J., Chen, K.M., Zhao, Z.G., Chen, G.C. and Zhou, W.J. (2008) Effects of silicon on defense of wheat against oxidative stress under drought at different developmental stages. Biologia Plantarum 52 (3): 592-596.

Gunes A., Pilbeam, D., Inal, A. and Coban, S. (2008) Influence of silicon on sunflower cultivars under drought stress, I: Growth, antioxidant mechanisms and lipid peroxidation. Journal of Soil Science and Plant Nutrition 39: 1885-1903.

Haahtela, K., Wartiovaara, T. and Sundman, V. (1981) Root-associated $\mathrm{N}_{2}$ fixation (acetylene reduction) by Enterobacteriaceae and Azospirillum strains in cold- climate spodsols. Appl. Environ. Microbiol. 41: 203-206.

Hattori, T., Inanaga, S., Araki H., Mortia, S., Luxova, M. and Lux, A. (2005) Application of silicon enhanced drought tolerance in sorghum bicolor. Physiolgia Plantarum 123: 459-466. 
Kaufman, P.B., Dayanandan, P., Franklin, C.I. and Takeoka, Y. (1985) Structure and function of silica bodies in the epidermal system of grass shoots. Ann. Bot. 55: 487-507.

Khan, S.M., Zaid, A. and Wani, P.A. (2006) Role of phosphate-solubilizing microorganisms in sustainable agriculture. INRA, EDP Sciences. Agron. Sustain. Dev. 27: $29-43$

Keshta, M.M. and El-Kholy, M.H. (1999) Effect of inoculation with N2-fixing bacteria, nitrogen fertilizer and organic manure on sunflower. Proc. of the International Symposium of Biological.

Kader, M.A., Mamun, A.A., Hossain, S.M.A. and Hasna, M.K. (2000) Effects of Azotobacter application on the growth and yield of transplant rice and nutrient status of post-harvest soil. Pakistan Journal of Biological Sciences 3: 1144-1147.

Korndorfer, G. H. and Lepsch, I. (2001) Effect of silicon on plant growth and crop yield. In: Silicon in Agriculture: Studies in Plant Science 8: 115-131.

Kumbhar, C. T. and Savant, N. K. (1999) Recycling of rice plant silicon and potassium on leaf scald management in rice. In: Conference Silicon in Agriculture. p. 30, 26-30 September , 1999, Fort Lauderdale, Florida, USA.

Lewin, J. and Reimann, B.E.F. (1969) Silicon and plant growth. Annu. Rev. Plant Physiol. 20: 289-304.

Leland, E. F. (1996) Salinity effect on four sunflower hybrids. Agron. J. 88: 215-219.

Lux, A., Luxova, M., Hattori, T., Inanaga, S. and Sugimoto, Y. (2002) Silicification in sorghum (Sorghum bicolor) cultivars with different drought tolerance. Physiol. Plant 115: 87-92.

Ma, J. F., Miyake, Y. and Takahashi, E. (2001) Silicon as a beneficial element for crop plants. In: Silicon in Agriculture: Studies in Plant Science 8: 17-39.

Ma, J.F. (2004) Role of silicon in enhancing the resistance of plants to biotic and abiotic stresses. Soil Sci. Plant Nutr. 50: 2002-2004.

Mahmoud, H.A.F. and Amara, M.A.T. (2000) Response of tomato to biological and mineral fertilizers under calcareous soil conditions. Bull. Fac. Agric., Cairo Univ. 51: $151-174$.

Mauad, M., Cruscio, C.A.C., Filho, H.G. and Correa, J.C. (2003) Nitrogen and silicon fertilization of upland rice. Scientia Agrícola 60 (4).

Mohamed, A.A.E. (2003) Response of sunflower to phosphorine and cerealine in inoculation under low NP-fertilizer levels. J. Agric. Res., Tanta Univ. 29 (2): 653-663.

Mohamed, M.A. and Ayman, A.M. (2009) The effect of Bio,Organic and Mineral fertilization on productivity of Sunflower seed and oil yields. J. Agric. Res., Kafer El-Sheikh Univ. 35 (4). 
Muhammad T., Sajjad, A., Muhammad, A., Muhammad, N., Haseebur, R. and Muhammad, A.S. (2013) Impact of Planting Time and Silicon Levels on Yield and Yield Components of Sunflower (Helianthus annuus L.). Pak. J. life soc. Sci. 11 (1): 60-64.

Muthukumar, T. and Udaiyan, K. (2006) Growth of nursery-grown Bamboo inoculated with arbuscular mycorrhizal fungi and plant growth promoting rhizobacteria in two tropical soil types with and without fertilizer application. New Forests 31 (3): 469485 .

Nawar, A. I. (1994) Response of sunflower varieties to mineral and Biofertilization with nitrogen. Com. in Sci. and Dev. Res. 47: 163-178.

Nautiyal, C.S. (1999) An efficient microbiological growth medium for screening phosphate solubilizing microorganisms. FEMS Microbiology Letters 170 : 265- 270.

Ogbo, F.C. (2010) Conversion of cassava wastes for biofertilizer production using phosphate solubilizing fungi. Bioresour. Technol. 101: 4120-4124.

Öhlinger, R. (1996) Phosphomonoesterase activity with the substrate phenylphosphate. In: "Methods in Soil Biology", F. Schinner, R. Öhlinger, E. Kandeler and R. Margesin (Ed.), pp.210-213, Springer, Berlin.

Radwan, F.I. (1996) Effect of mycorrhizae inoculation, phosphorus and potassium fertilization on growth, yield and its components of sunflower plants. J. Agric. Res., Tanta Univ. 22 (3): 357-375.

Revillas, J.J., Rodelas, B., Pozo, C., Martinez-Toledo, M.V. and Lopez, J.G. (2005) Production of amino acids by Azotobacter vinelandii and Azotobacter chroococcum with phenolic compounds as sole carbon source under diazotrophic and adiazotrophic conditions. J. Appl. Microbiology 4 : 421-425.

Saleh, S.A., Abd-El-Gwad, N.M. and Omran, A.A.M. (2004) Response of some sunflower cultivars to some Bio-Nitrogen Fertilization under hill spaces. J. Agric. Sci. Mansoura Univ. 29 (12): 6775- 6786.

Shaukat, K., Afrasayab, S. and Hasnain, S. (2006) Growth responses of helianthus annuus to plant growth promoting rizobacteria used as a biofertilizers. Int. J. Agric. Res. 1: 573-581.

Shehata, M.M. and El-Khawas, S.A. (2003) Effect of two biofertilizers on growth parameters, yield characteristics, nitrogen components, nucleic acid content, minerals, oil content, protein profiles and DNA bending pattern of sunflower (Helianthus annaus L. cv. Vedock). Field Pak. J. Biol. Sci. 6 : 1257-1268.

Shengyi X., Qishan, W., Xia, S. and Wang, Q.S. (1999) Studies on the effect of silicon fertilizer on cotton. China-Cotton 25: 6-7.

Singh, K., Singh, R., Singh, K.K. and Singh, Y. (2007) Effect of silicon carriers and time of application on rice productivity in rice-wheat cropping sequence. International Rice Research Notes 32 : 30-31.

Egypt. J. Soil Sci. 53, No. 4 (2013) 
Takahashi, E., Ma, J.F. and Miyake, Y. (1990) The possibility of silicon as an essential element for higher plants. Comm. Agric. Food Chem. 2 : 99-120.

Visser, S. and Dennis, P. (1992) Soil biological criteria as indications of soil quiantity: Soil microorganisms. American J. of Alternative Agriculture 7: 33-37.

Yasari, E. and Patwardhan, A.M. (2007) Effects of (Azotobacter and Azospirillium) inoculants and chemical fertilizers on growth and productivity of canola (Brassica napus L.). Asian J. Plant Sci. 6 : 77-82.

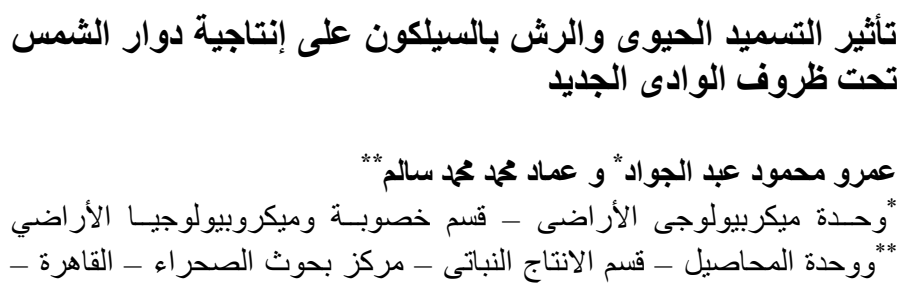

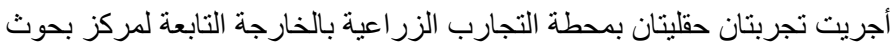

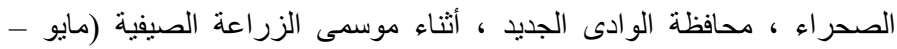

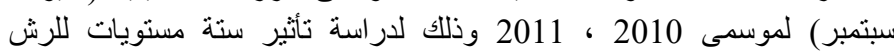

بالسيليكون ( بدون ، 200 ملجم/لتر سيليكون ، 2010 ، 400 ، 600 ، 600 ، 800 ،

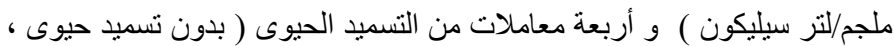

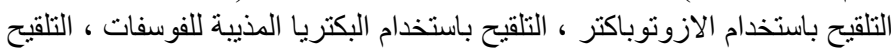

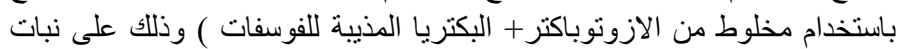

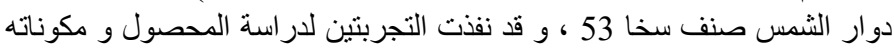

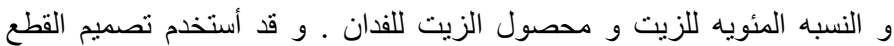

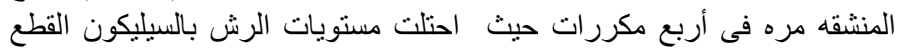
الرئيسيه فى حين وز عت معاملات التسميد الحيوى فيى القطع الثقيه.

$$
\text { و يمكن تلخيص النتائج المتحصل عليها فيما يلى: ولئ }
$$

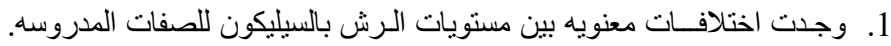

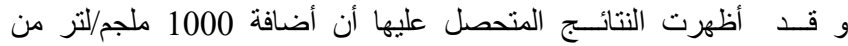

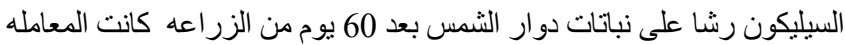

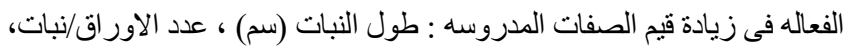

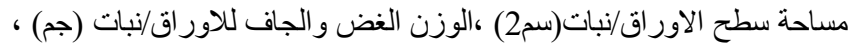

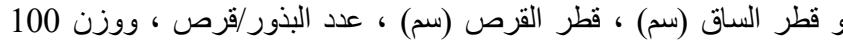

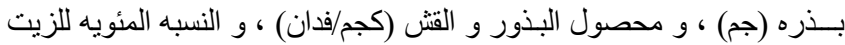

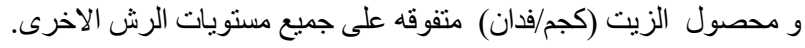


2. كما أثنارت النتائج المتحصل عليها الى وجود اختلافات معنويه بين معاملات

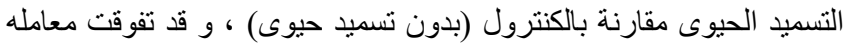

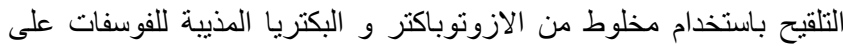

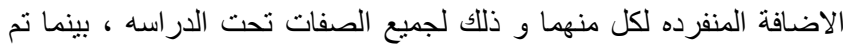

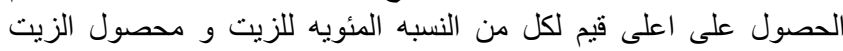

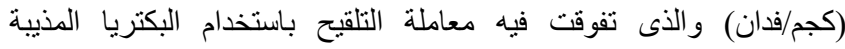

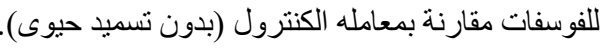

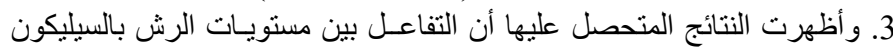

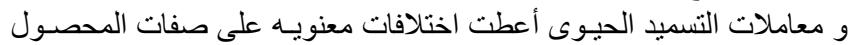

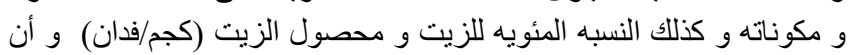

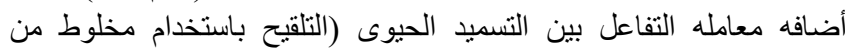

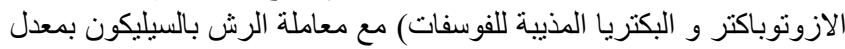

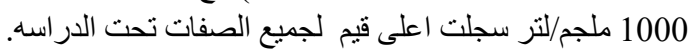

و قد خلصت الدراسه للتوصيه بأضافه التسميد الحيوى (التلقيح باستخدام

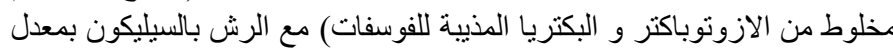

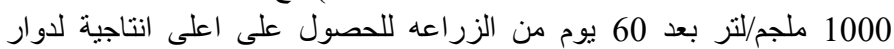

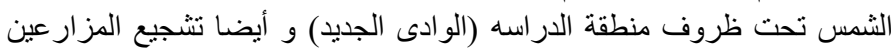

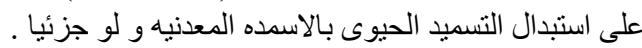

